\title{
IMMIGRANT-EARLY CHILDHOOD EDUCATOR'S EXPERIENCE OF WORKING WITH IMMIGRANT CHILDREN AND THEIR FAMILIES: ARTS-INFORMED NARRATIVE INQUIRY SELF-STUDY
}

\author{
by \\ Oi Ling Helen Kwok, M.A., 2017 \\ Ryerson University, Toronto, Ontario, Canada \\ A Masters Research Paper \\ Presented to Ryerson University \\ In partial fulfillment of the Requirements for the degree of \\ Master of Arts in the Program of Early Childhood Studies
}

Toronto, Ontario, Canada, 2017

(C) Oi Ling Helen Kwok 2017 


\begin{abstract}
AUTHOR'S DECLARATION
I hereby declare that I am the sole author of this thesis. This is a true copy of the thesis, including any required final revisions, as accepted by my examiners.
\end{abstract}

I authorize Ryerson University to lend this thesis to other institutions or individuals for the purpose of scholarly research.

I further authorize Ryerson University to reproduce this thesis by photocopying or by other means, in total or in part, at the request of other institutions or individuals for the purpose of scholarly research.

I understand that my thesis may be made electronically available to the public. 


\title{
IMMIGRANT-EARLY CHILDHOOD EDUCATOR'S EXPERIENCE OF WORKING WITH IMMIGRANT CHILDREN AND THEIR FAMILIES: ARTS-INFORMED NARRATIVE INQUIRY SELF-STUDY
}

(C) Oi Ling Helen Kwok 2017

Master of Arts

Early Childhood Studies

Ryerson University

\begin{abstract}
Early years educational settings are often the first social environment that new immigrant children and their families engage in. Research in the field of education shows that immigrant children and their families are often best served by the educators, who themselves, are also immigrants. It is believed that immigrant educators are culturally knowledgeable and responsive to the needs of the children due to the shared immigration experiences and/or mother language. To gain a better insight into an immigrant-Early Childhood Educator's experience of working with immigrant children and their families, I engage in a self-study using Connelly and Clandinin's Narrative Inquiry. By engaging in Narrative Reflective Process, a series of creative art activities as data collection, I gather and reflect on my lived experiences to deepen my understanding into what may be most significant to immigrants. Three narrative patterns (challenges in a new home, a sense of belonging, perseverance) emerge within and across the told stories. Through my inquiry I invite all Early Childhood Educators to consider these in their own practice, as well as to reflect upon their own personal-professional experiences, through creative selfexpression approaches, and so to ponder how their values and beliefs might inform their professional practice.
\end{abstract}




\section{ACKNOWLEDGEMENTS}

I would like to thank my research supervisor, Dr. Jasna K. Schwind for providing me with expertise and guidance throughout this challenging and rewarding process. Thank you for believing in my abilities and inspiring me to embrace this learning and research journey. I sincerely appreciate the patience, knowledge, understanding, encouragement and kindness you have shown me as you went above and beyond many times. The commitment you have for me is exemplary and greatly appreciated.

I would also like to thank my second reader, Dr. Rachel Berman for offering me tremendous support and insightful feedback on my research. I am grateful for the time and effort you contributed to this project.

I would love to thank my husband Justin for having faith in me and for encouraging me to challenge my boundaries. I am forever thankful for your unconditional love and support that continue to inspire me to be my best in every aspect of my life. 


\section{TABLE OF CONTENTS}

AUTHOR'S DECLARATION

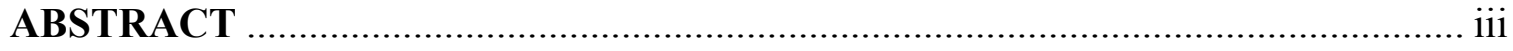

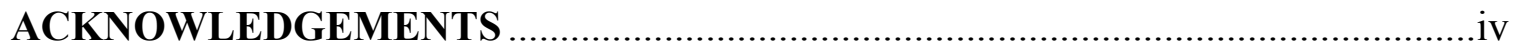

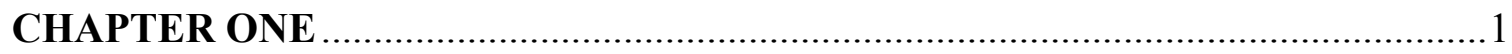

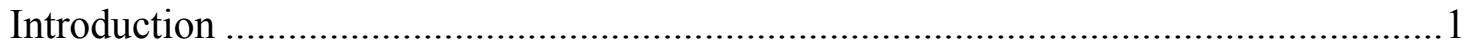

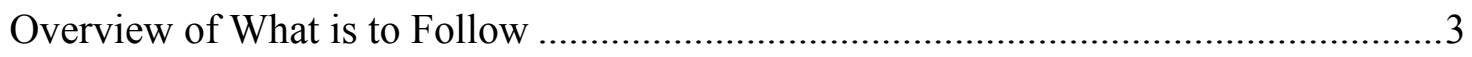

CHAPTER TWO

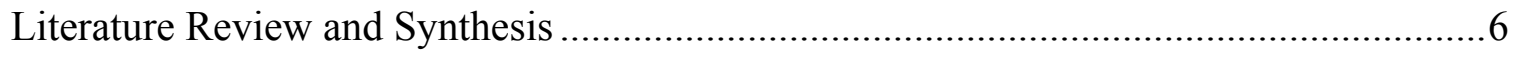

Definition of Immigrant........................................................................................

Educators' Exposure to Immigrant Children and Families .......................................8

Educators' Cultural Assumptions and Self-Awareness .........................................

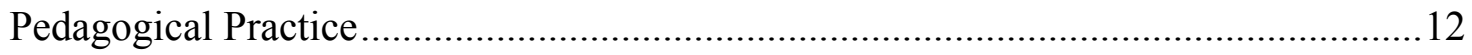

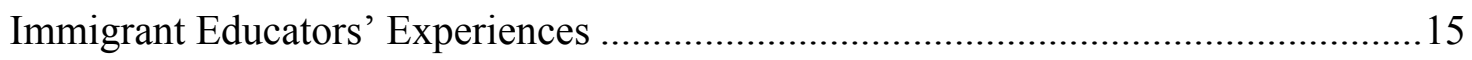

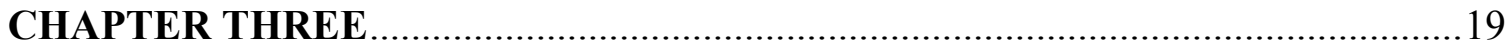

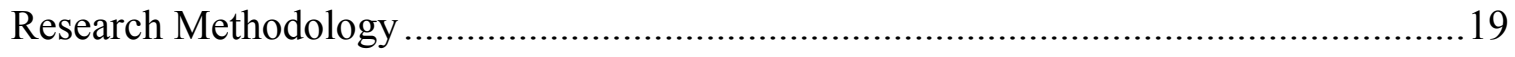

Historical Development of Narrative Inquiry ....................................................20

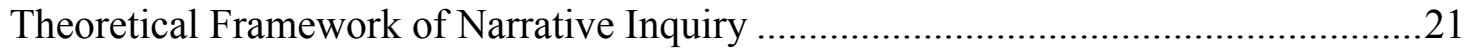

Three-Dimensional Space of Narrative Inquiry .................................................22

Four Directions in the Study of Experience ..........................................................24

The Three Levels of Justification ...........................................................................25

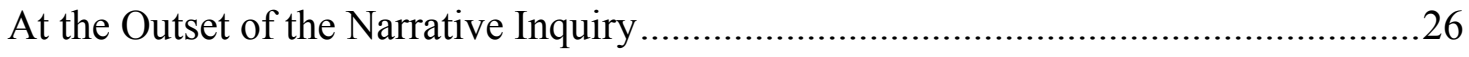

During the Stage of Data Analysis and Interpretation............................................26 
How I Use the Three Levels of Justification in this Self-study ..................................27

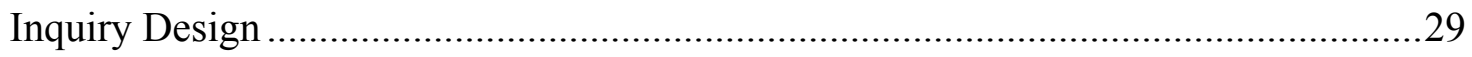

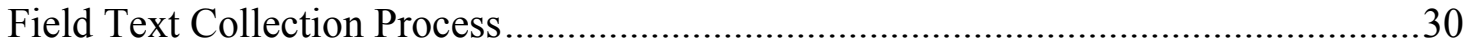

The Narrative Reflective Process ............................................................................ 31

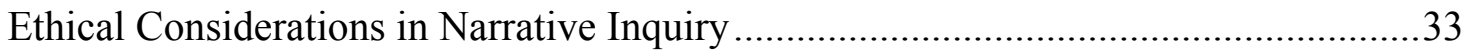

The Potential Concerns of Self-Study in Narrative Inquiry .....................................35

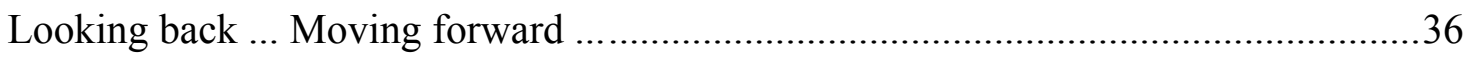

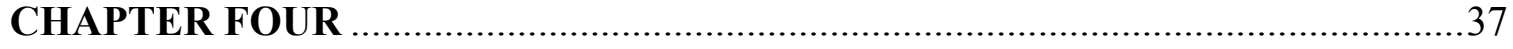

Skipping Stones Across the Ocean: Personal Justification ......................................... 37

Story One: Learning from my Grandfather's Wisdom...........................................38

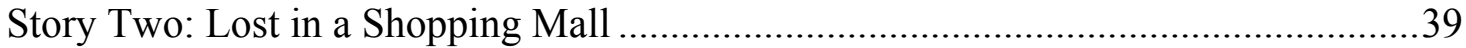

Story Three: Honouring the Confucian Value as the First Born Child - 仁 (Humanness)

Story Four: Living with a Different Family ................................................42

Story Five: A Bruise on Mrs. Weareok ..............................................................43

Story Six: Losing Touch with my Homeland ....................................................... 45

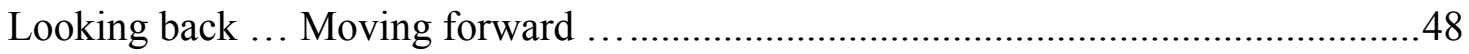

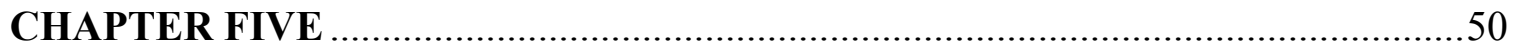

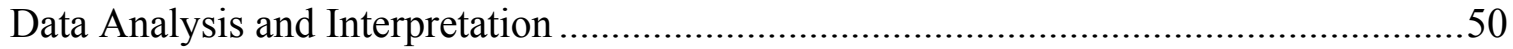

Second Level of Analysis: Practical Justification ..............................................50

Theoretical Framework: Three-Dimensional Space of Narrative Inquiry ....................51

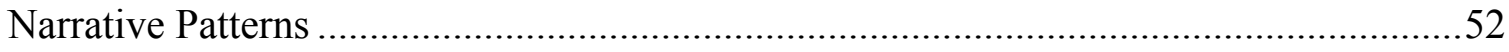

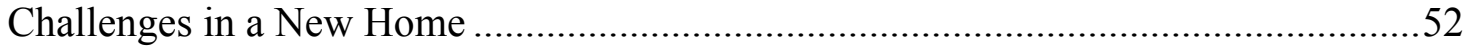




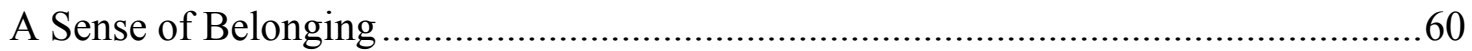

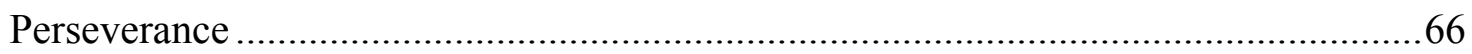

Looking back ... Moving forward .............................................................................72

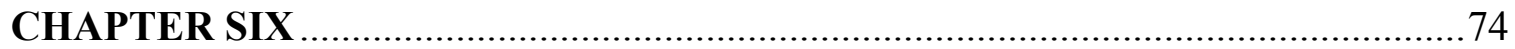

Third Level of Analysis: Social Justification ...............................................................

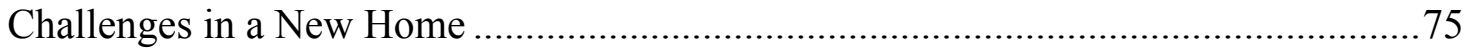

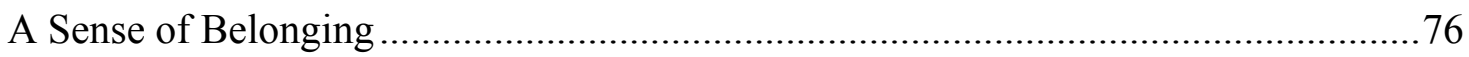

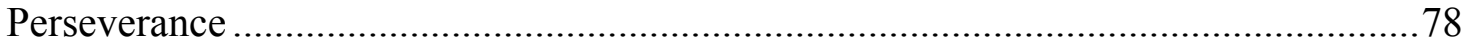

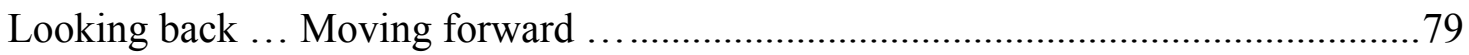

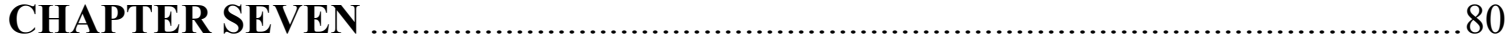

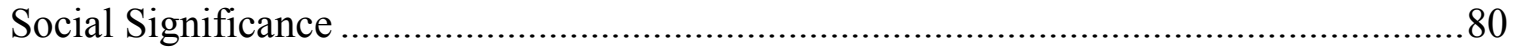

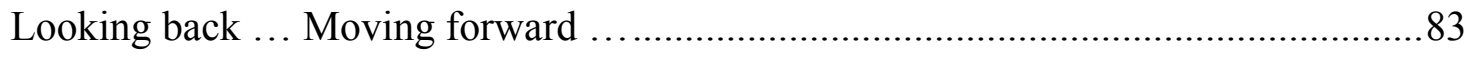

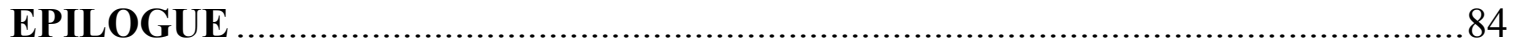

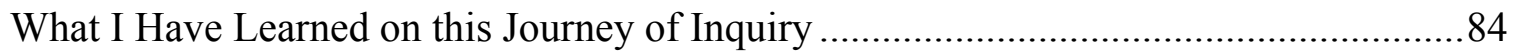

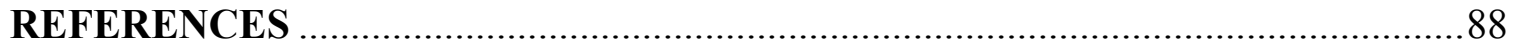

Appendix A: Research Ethics Board Approval Form …………............................102 


\section{CHAPTER ONE}

\section{Introduction}

I am seventeen years old. With two pieces of luggage and a dictionary, I arrive at Toronto Pearson International Airport, alone. Standing in front of an immigration officer, I am nervous and scared. At first, he is flipping through my passport and typing information into the computer. When he asks me the reason for my visit, my mind immediately answers, “我唻加拿大係為尋找我好好㕷將來” (I am here to search for a better future), but I hold back. I tell him I am here to study. "Welcome to Canada!" he says. That is how my life journey, as an immigrant, begins.

Being an immigrant in Canada was a challenging experience for me. I did not speak English fluently nor understand how the Canadian system worked, including

healthcare, education, transportation, employment, and culture. In addition to having a difficult time adjusting to the new cultural environment, I had a negative living experience with my extended family in Canada. This experience is one of the told stories, in chapter four. On the other hand, I found comfort at school. I formed great friendships, especially with peers, from my country of origin. We supported and encouraged each other to overcome our challenges. I felt more comfortable befriending them, as we shared similar cultural values, perspectives, and beliefs.

I was always told that Canadian working experience is important for new immigrants, if we want to succeed. Working in a summer camp was one of my first jobs in Canada. Being insecure about my ability to communicate, I decided to devote more time to observation. I partnered with a lead counsellor to supervise a group of preschool children. I was inspired by her skills in interacting with the children, designing appropriate activities that foster children's development, and demonstrating strategies for 
positive child guidance. When I shared how I felt about her practice, she said, "This is part of what an Early Childhood Educator strives to do." That was the first time I was exposed to the profession. During the experience, children were able to be who they were in a harmonious environment. Most importantly, they did not judge me on my English skills and continued to communicate with me. While they were allowed to be who they were, I was able to be who I was. This sense of acceptance and empathy deepened my interest in exploring the field of Early Childhood Education.

With years of pre-service and in-service training, I have finally become an Early Childhood Educator. Throughout my professional practice, I provided care for and developed trusting relationships with a number of immigrant children and their families. As I learned about each of their unique personal stories, their immigration experiences were what resonated most. Their experiences reminded me of my own experiences. Mine, however, were left undiscovered. Although I established my career path in Canada, my identity as an immigrant remains. My identity as an immigrant is relevant to who I am and what I do as an Early Childhood Educator, while working with immigrant children and their families.

Being a graduate student, I now have the opportunity to reflect on my personal and professional knowing within the academic community. I am able connect my past to my present, which encourages me to envision my future role in the broader professional and societal contexts. This learning journey increases my awareness of myself and the recognition of how my role, as an immigrant-Early Childhood Educator, influences the lives of those I care for and work with. By uncovering my stories, I hope to inspire other Early Childhood Educators to do the same, so that we become more aware of how our 
personal and professional values, practices, attitudes, and qualities may contribute to our community, society, and humanity.

\section{Overview of What is to Follow}

As I begin my inquiry, I invite you, the reader, to join me in this exploratory process. Narrative Inquiry is a qualitative research method, which allows me as an inquirer, in this self-study, to examine my own unique experiences in a systematic and sophisticated way. Using the three-dimensional space (temporality, sociality, place) and four directions (inward and outward, backward and forward) of Narrative Inquiry (Connelly \& Clandinin, 2006), I am able to gain a deeper understanding of the inquiry puzzle, How do I, as an immigrant-Early Childhood Educator (ECE), experience working with immigrant children and their families? To ensure you are fully prepared to follow the progress along with me, I provide an overview of the content of each chapter.

In Chapter One, I begin with my own story of being an immigrant. I illustrate how I have become an Early Childhood Educator and the reason for the choice of my inquiry puzzle. In Narrative Inquiry, this is the personal justification for the self-study.

In Chapter Two, I present the review of literature on the inquiry topic, to situate my self-study in the practical and the social justifications of Narrative Inquiry.

In Chapter Three, I describe the methodology of Narrative Inquiry, including its historical development, philosophical underpinnings, three levels of analytical justifications (personal, practical, social), and ethical considerations. I briefly introduce the meaning and purpose of using an arts-informed approach in the inquiry, followed by the description of the inquiry design - self-study. I then explain the use of the data collection tool, Narrative Reflective Process (Schwind, 2008) and how I engage in the 
collection and analysis process of the data, which is referred to as the field text in Narrative Inquiry.

In Chapter Four, I enter the first level of data analysis and interpretation of Narrative Inquiry (personal justification). Using the three-dimensional space and four directions of experience, I engage in an interwoven dialogue style and demonstrate the multiple "I's" of Narrative Inquiry (Clandinin \& Connelly, 1998, 2000): my inquirer-self interjects my personal told stories of being a grandchild, first-born child, immigrant, and Early Childhood Educator.

In Chapter Five, I move into the second level analytical process (practical justification). I critically examine the told stories and identify the emerging narrative patterns within and across the stories. Here I integrate relevant literature to analyze these patterns to deepen my understanding of the inquiry within the context of the Early Childhood Education profession.

In Chapter Six, I continue to use the theoretical lens of Narrative Inquiry, as I enter the third level of analysis (social justification). I discuss the significance and implications of the inquiry in the broader context of society.

In Chapter Seven, I write a letter to immigrant children in response to the significance gathered from the three levels of justification. Through this letter, I express my commitment to the children and their families and the strategies I use to support the immigrant population in my care as an Early Childhood Educator and a human being.

I end this MRP with an Epilogue by reflecting on my quest to undertake this inquiry and my new understanding of my own experiences of working with immigrant children and their families, as an immigrant-Early Childhood Educator. I share with you, 
dear reader, what I learned and where I am heading, and invite you to enter your own self-inquiry to consider your own life stories and how they may contribute to your professional role.

In the next chapter, I review and synthesize the literature related to the inquiry, and identify the gaps in existing research. 


\section{CHAPTER TWO}

\section{Literature Review and Synthesis}

In this chapter, I review and synthesize the existing body of literature relevant to the inquiry puzzle, How do I, as an Immigrant-Early Childhood Educator (ECE), experience working with immigrant children and their families?

Immigrant children are the fastest growing segment of the North American child population (Capps et al., 2006; Hernandez \& Cervantes, 2011; Keengwe \& Oncwari, 2014; Thomas \& Kearney, 2008). Often, childcare centres and schools are the first social institutions that new immigrant children and families access. Recognizing this, various authors have found that educators play a key role in facilitating immigrant children's integration and learning in a new classroom environment (Tsung, Freeman, \& White, 2007; Vuckovic, 2008). To support educators in working with the diverse needs of children and their families, a body of research focuses on providing effective strategies for their pedagogical practices (Beyer, 2010; Johnson \& Larke, 2012; Keat, Strickland, \& Marinak, 2009; Kirova, 2001) and exploring the impact of educators' awareness of and exposure to cultural diversity on their professional practice (Buchori \& Dobinson, 2015; Chen, Nimmo, \& Fraser, 2009; Han \& Thomas, 2010; Johnson \& Larke, 2012; Thomas \& Kearney, 2008).

Despite a great number of studies examining primary school educators' experiences of working with immigrant children and their families in the United States and Australia (Delano-Oriaran \& Meidl, 2012; Kirova, 2001; Mohr \& Mohr, 2007; Thomas \& Kearney, 2008), such research within the Canadian context is limited (Brandon, 2004; Bernhard, Hyman, \& Tate, 2010). The existing Canadian research 
focuses mainly on external factors (pre-service training, professional development, etc.) influencing the ECEs' understanding of how to support immigrant children and their families (Kwok, 2015). One exception to these studies is Pemberton and Tremblay's (2016) examination of the strategies that the ECEs, at a childcare center in Ottawa, use to ease the needs and integration for newcomer Syrian families. Nevertheless, little consideration is paid to an individual ECE's unique experience of working with immigrant children and their families, and especially for ECEs who are immigrants themselves.

Thus, I, as a researcher, Early Childhood Educator and an immigrant, elect to use the Arts-Informed Narrative Inquiry (AINI) (Schwind, Lindsay, Coffey, Morrison, \& Mildon, 2014) self-study approach to reflect on and examine my own experiences of working with immigrant children and their families. Using Narrative Inquiry qualitative research approach, and its theoretical lens of the three-dimensional space (Connelly \& Clandinin, 1990, 2006; Dewey, 1997), and Schwind's Narrative Reflective Process (2008), as a data collection tool, I delve into my personal and professional experiences to learn how these inform who I am as an Early Childhood Educator, and how that knowledge may augment my future practice.

\section{Definition of Immigrant}

An immigrant is typically defined as an individual who has moved from their country of origin and settled permanently in another country, if they wish to, for becoming a citizen of that country (Canadian Council for Refugees, 2010). According to Citizenship and Immigration Canada (CIC) (2010), to be more specific, an immigrant is a person who is, or has been, a landed immigrant in Canada. A landed immigrant refers to 
a person who has been granted the right to live in Canada permanently by the immigration authorities and obtain the citizenship. From the CIC's standpoint (2010), a landed immigrant is entitled to immigration and settlement services, such as English Learning classes, employment support, and community integration programs.

Researchers argue that, regardless of whether an individual is newly arrived or has lived in Canada for many years, these individuals remain one of the most vulnerable populations and may need extra supports even after they become Canadian citizens (Boyd, 2006; Chuang \& Moreno, 2011; Kirmayer et al., 2011; Lewis-Watts, 2006).

Within the literature, researchers exploring the topic surrounding immigrant children and families, mainly define them as individuals who are linguistically, culturally, ethnically, and racially diverse (Beyer, 2010; Johnson \& Larke, 2012; Keat et al., 2009; Tsung et al., 2007). For the purpose of my inquiry, I use the term immigrant for individuals who have a culturally, racially, and linguistically diverse background due to migration to Canada, regardless of the length of their residency.

\section{Educators' Exposure to Immigrant Children and Families}

Numerous researchers focus their attention on educators' understanding of and exposure to working with children of culturally diverse backgrounds (Goodwin, 2002; Johnson \& Larke, 2012; Thomas \& Kearney, 2008). Goodwin (2000) suggests that educators' social environment, including personal and professional, is associated with their ability to work with immigrant children. Thomas and Kearney (2008), for example, found that amongst the three hundred and four educators in Australia, over one-quarter of them agreed that their confidence in dealing with immigrant children was associated with how much they understood a specific culture. They felt most comfortable with children of 
European descent, because they had more experience working with European children, than those from other cultural backgrounds. The Massachusetts Teachers Association (2008) shows that pre-service education contributes to educators' confidence in working with immigrant children. In-service educators recalled and stressed that the content of diversity is based primarily on theory, which made it very difficult to apply in practical field experiences. Johnson and Larke (2012) also reveal that in-service and pre-service educators, particularly in Texas, felt ill-prepared to work with children from different cultures, as the areas where they live and work, are predominantly white, sharing similar beliefs and customs.

Hence, educators in Australia and the U.S believe their lack of exposure to cultural diversity during pre-service training affects their competence in working with immigrant children and their families. Whether or not they feel more comfortable with non-immigrant children, it is important to recognize that our social environment, including the people with whom we work, socialize, and study shapes how we think, feel, and behave in those contexts. In my inquiry, I explore how my exposure to immigrant children and families, my own migration to Canada, as well as in-service experiences, impact my professional relationships with children in my care.

\section{Educators' Cultural Assumptions and Self-Awareness}

ECEs play an important role in building good relationships with immigrant children and parents they serve (Adair, 2011; Ali, 2012; Han \& Thomas, 2010; Strickland, 2012; Tsung et al., 2007). To accomplish this, researchers contend that ECEs' recognition of their own assumptions and awareness of cultural diversity is key in supporting their professional growth while working with immigrant children and their 
families (Buchori \& Dobinson, 2015; Chen et al., 2009; Han \& Thomas, 2010). With the majority of ECEs in the United States being middle-class and of European-decent, researchers found that teachers' awareness of their own biases and assumptions is crucial, as it contributes to their relationships with, and the experiences of, immigrant children in the classroom (Han \& Thomas, 2010; Ladson-Billings, 2006; Nieto \& Bode, 2008). For example, educators are frequently influenced by culturally inaccurate assumptions that immigrant parents do not want to interfere with their children's education (Adair, 2011; Expósito \& Favela, 2003). In some cultures, teachers are viewed as authority figures and knowledge holders (Peeler \& Jane, 2005). Thus, parents' passive way of being involved in their children's education may be a form of respect and trust for the teachers, rather than a desire to be disengaged in their child's schooling. Educators' inaccurate assumptions may misinterpret parents' behaviour and approaches toward their children's academic performance.

Research also reveals that educators' personal assumptions not only lead to their misinterpretation of immigrant parents, but also their children. Strickland (2012), using video-based stimulated recall methodology, found that educators assumed children's irresponsiveness to class discussions and questions was due to limitations in their language proficiency. On the other hand, children indicated that such classroom behaviour was a sign of modesty. To minimize cultural misunderstandings and assumptions, researchers advise educators to interact with immigrant children and parents through open communication and attentive listening (Adair, 2011; Ali, 2012; Curran, 2003; Han \& Thomas, 2010; Kirova, 2001). 
A number of early childhood educators shared how their assumptions about cultural or ethno-linguistic groups were generalized and shaped by their own family, friends, media and interactions with people from other cultures (Buchori \& Dobinson, 2015). It is important to note that educators' social environment, as well as their personal assumptions, shape their abilities of working with immigrants (Buchori \& Dobinson, 2015; Goodwin, 2002; Johnson \& Larke, 2012; Thomas \& Kearney, 2008). Early childhood educators further admitted being unaware of their own cultural prejudices and biases, which consequently projected a negative attitude towards immigrant children and families, affecting their practice in the classroom. They became disinterested in learning about the individual needs of children and so adopted a "one-size-fits-all" approach when designing curriculum (p.75). To counter this indifference, Sue and Sue (2003) highlight the essence of increasing one's awareness of his or her own cultural identity and understanding of how that identity shapes his or her perspectives on teaching and learning with children from culturally diverse backgrounds. Some research (Adair, 2011; Buchori \& Dobinson, 2015; Han \& Thomas, 2010; Kurbegovic, 2016; Nieto \& Bode, 2008) also suggests that teachers' awareness of their personal-social identity, their personal-cultural-professional values, biases, preconceived notions, and personal limitations while working with immigrant children and families, is a valuable starting point.

In summary, the literature highlights the importance of educator's self-awareness and assumption of cultural diversity as it influences the educator-child relationships and their professional practices. Using the Arts-Informed Narrative Inquiry self-study (AINI) approach, I critically reflect on the external elements surrounding me (family, peers, 
teachers, co-workers, and community), as well as my internal self (assumptions, beliefs and values) to deepen my understanding of how I view and engage with immigrant children and families in my professional role of Early Childhood Educator. In other words, by delving into who I am as a social and cultural being, using arts as a selfexpressive instrument, I become more aware of how I co-construct my personalprofessional identity, which impacts my professional relationships with immigrant children and their families.

\section{Pedagogical Practice}

Implementing an effective pedagogical practice has been consistently highlighted as one of the integral aspects that supports immigrant children's learning in the classroom and provides educators with a positive professional experience (Adair, 2011; Ali, 2012; Curran, 2003; Kirova, 2001; Mohr \& Mohr, 2007; Tsung et al., 2007). Using immigrant children's narratives, Kirova (2001) suggests the use of non-verbal communication (smiles and getting down to children's level) and physical space (furniture arrangement) as effective strategies to support immigrant children who are feeling lonely in a new environment. Curran (2003) agrees with the benefits of using appropriate body language and visual representations while interacting with the children and their parents. However, educators insist that language barriers continue to hinder them from gaining a better understanding of the immigrant children's needs, especially their emotional needs, which in turn affects their ability to foster effective educator-child interactions and relationships (Curran, 2003; Kwok, 2015; Mohr \& Mohr, 2007).

To mitigate the communication gap, Mohr and Mohr (2007) found that educators intentionally involved children in verbal interactions. In their observation, the educators 
focused heavily on children's linguistic development and frequently initiated the conversations for the purpose of giving children more opportunity to learn different words. Curran (2003) argues that if children's first language is valued and encouraged to be used within the classroom, they would feel more comfortable and would easily adapt to learning English. To support this idea, Adair (2011) reached out to forty-five immigrant preschool educators, using focus group interviews, and listened to their perspectives on the emphasis of children's linguistic performance. Results show that the "modelling approach" (p. 61) used by the non-immigrant educators, which asks children to repeat the words the educators speak, was ineffective. This "modelling approach" contradicts the early childhood education philosophy used in the U.S, which is centered on the idea that children should be recognized as co-constructors of their knowledge, not just be told what to learn and how to learn it (DeVries, Zan, Hildebrandt, Edmiaston, \& Sales, 2002).

The reviewed studies are mostly conducted, using interviews, surveys, and observations, to investigate a collective perspective of educators regarding the impacts and challenges that contribute to their pedagogical practices working with immigrant children. Highlighting the issues shared among a large number of educators may help increase public and institutional focus to provide supports for the educators. However, examining only the recurring themes, minimizes the value of educator's personal background and unique lived experiences within particular contexts, and how these elements contribute to their professional decisions and approaches.

To support the idea that educators' lived experiences and insights are the essence of constructing knowledge and meaning in their practice, a number of researchers 
highlight the need to invoke the reflective voices of ECEs (Chen et al., 2009; Expósito \& Favela, 2003; Lee \& Dallman, 2008; Meier \& Stremmel, 2010). In Expósito and Favela’s (2003) ethnographic study, they invited four novice ECEs to share their experiences working with immigrant children and families. The educators reflect on their previous experiences and belief systems, and critically examine how they impact their interactions with the children and their families. Although valuable insights were gained, the voices and individual stories of immigrant ECEs are lost, as only the themes were captured. In order to fully access educators' personal and professional lived experiences, narrative research is a useful approach that allows ECEs' voices to emerge through the told stories.

Meier and Stremmel (2010) view Narrative Inquiry as a beneficial research methodology for the field of early childhood education. They emphasize that ECEs who engage in Narrative Inquiry study "seek ways of enriching and transforming that experience for themselves and others" (p. 250). It provides a way in which they can identify the truths they hold about themselves and their experiences inside and outside a specific context, and how they can be continually negotiated and reconstructed within the educators themselves and with others.

Therefore, in this Narrative Inquiry, using a self-study approach, I tell stories of my life experiences, exploring my identity, values, feelings, perspectives, and knowledge. I critically analyze these stories, using the three-dimensional space of Narrative Inquiry (further explained in Chapter 3), while delving into scholarly literature to more fully understand my professional role as an Early Childhood Educator, who is also an immigrant. 


\section{Immigrant Educators' Experiences}

The challenges that confront the teaching experiences of immigrant educators have not been fully investigated within the educational and research contexts (Adair, 2011; Goodwin, 2002; Suarez-Orozco \& Suarez-Orozco, 2001). However, Niyubahwe, Mukamurera and Jutras (2013) undertook a literature review to identify and summarize the challenges of integration into the school system of primary teachers, who themselves recently immigrated to Canada and other western countries. These challenges include language barrier, problems related to adjusting to the school culture and the teaching team, as well as issues related to teaching practice.

Language barrier. Many immigrant educators propose that their professional integration into the school system is greatly influenced by their language proficiency. The two studies conducted with immigrant educators in Ontario found that they felt insecure about being perceived as outsiders because of their accent and the lack of fluency in English (Myles, Cheng, \& Wang, 2006; Phillion, 2003). Their lack of mastery of English affected their confidence and limited their capacity to teach effectively (Cruickshank, 2004; Hutchison, 2005). In the U.S, immigrant educators disclosed that, due to their accent, they were refused employment and the parents expressed concerns for their children's education (Gordon, 1996; Hutchison, 2005). To minimize their language barrier, immigrant educators participated in language training to reduce their accent (Hutchison, 2005).

Problems related to adjusting to the school culture and teaching team. Immigrant educators not only have difficulty integrating into a new professional environment, but they also have to learn how to work cooperatively with other teachers 
(Niyubahwe et al, 2013). With the language barrier, educators highlight the tension involved, as they try to establish positive relationships and collaborations with their colleagues (Myles et al., 2006; Phillion, 2003). As minorities, they share their sense of social isolation from their Canadian colleagues at their workplace (Bascia, 1996). They expressed that their Canadian colleagues tend to create superficial conversations with the immigrant educators and show indifferent attitudes and mistrust towards them. While immigrant educators pursued building a collaborative relationship with their Canadian colleagues, these colleagues refused to share professional knowledge and support (Phillion, 2003). This negative treatment and attitude can cause extreme insecurity and professional isolation, which affects the immigrant educators' confidence (Peerler $\&$ Jane, 2005).

Issues related to teaching practice. Immigrant educators are likely to encounter problems adapting to the pedagogical model implemented in the host country (Cruickshank, 2004; Hutchison, 2005; Myles et al., 2006; Wang, 2003). Wang (2003) notes that immigrant educators from China felt disoriented after experiencing the differences in teaching models in Toronto schools. Peeler and Jane (2005) identify this internal tension to be caused by immigrant educators' traditional teaching practice, in which they are expected to be the knowledge holders who transmit textbook knowledge directly to their students. Therefore, they expressed the challenge of applying Western philosophy, which requires them to change their role to a co-constructor, facilitator, and co-learner (Seah, 2005; Wang, 2003).

Whether in Canada or the U.S, immigrant educators, as much as the Canadian born educators, are required to learn how to work in the classroom with children of 
culturally diverse backgrounds (Peeler \& Jane, 2005; Niyubahwe et al, 2013). Wang (2003) indicates that educators of Chinese origin develop a sense of anxiety and fear, while navigating between three sets of cultural systems: Canadian, multicultural, and their own. Researchers suggest that the linguistic, social, cultural, and pedagogical struggles contribute to immigrant educators' overall experiences integrating in the school system (Niyubahwe et al, 2013; Remennick, 2002; Wang, 2003). Thus, the school team and all the members of the community should reflect on the support of professional integration for immigrant educators. They should recognize the systemic obstacles that these educators face, and adopt clear procedures for their social and professional integration, in order to discover what they have to offer in fostering student success.

\section{In Conclusion}

Based on the review of the literature, it is evident that the majority of the research focuses on the challenges faced by elementary school educators, rather than Early Childhood Educators, while working with immigrant children and their families. A breadth of literature focuses on educators' pre- and in-services experiences and the strategies (cultivating self-awareness and reflecting cultural assumptions) to improve their communication and practices within the classroom. Yet, educators' successful tools and strategies are often not highlighted. While most of the studies examine educators' experiences in Australia and the U.S, specifically in primary school, there is a lack of research exploring ECEs' experiences, especially for immigrant ECEs, of working with immigrant children and their families in Canada.

Although there is a growing interest in discovering the perspectives of immigrant educators on their working experiences within multicultural classrooms, non-immigrant 
educators' point of view continues to receive more attention within this research topic. Despite qualitative approaches using interviews with the participants, there is little research investigating educator's unique self as a person and a professional. To minimize the gaps in the existing literature and make sense of my own experiences as an immigrant-Early Childhood Educator who works with immigrant children and their families, I explore, using Arts-informed Narrative Inquiry self-study approach, my personal and professional identity. By adopting AINI and Schwind's Narrative Reflective Process (2008), my personal and professional experiences are revealed through creative self-expression and critical reflection. My purpose for this study is to deepen my understanding of who I am as an immigrant-Early Childhood Educator in Canada and how I engage with immigrant children and their families. If my Narrative Inquiry works, then my stories will move readers to engage in their own self-inquiry into their own personal-professional experiences practice, and so demonstrate the transferability of narrative research. 


\section{CHAPTER THREE}

\section{Research Methodology}

In this chapter, I delve into the research methodology I adopt for this study: Narrative Inquiry (Connelly \& Clandinin, 1990, 2006). I capitalize Narrative Inquiry to denote Connelly and Clandinin's prominent research framework, and so distinguish it from other narrative research approaches (Lindsay \& Schwind, 2016).

Throughout this study, I address the philosophical and the theoretical underpinnings of Narrative Inquiry. Specifically, I describe Connelly and Clandinin's conceptualization of the three commonplaces (temporality, sociality, and place), four directions (inward, outward, backward, and forward) of inquiry, and the three justifications (personal, practical, and social) for studying and analyzing a particular phenomenon. To embark on the journey of Narrative Inquiry, I highlight the guided creative data collection tool, Narrative Reflective Process (Schwind, 2008, 2016), I use in this self-study.

\section{Narrative Inquiry: The Pathway to Discovering Human Experiences}

Narrative Inquiry is a methodology for studying human lived experience as told through story (Connelly \& Clandinin, 1990). It holds a strong belief that human beings are natural storytellers, who live and tell stories about their living. Within the Narrative Inquiry research context, people shape their daily lives through stories of who they and others are (Connelly \& Clandinin, 2006; Lindsay \& Schwind, 2016). While humans live and tell stories of their experiences, narrative inquirers focus on a specific phenomenon of interest. They begin to critically and systemically analyze, interrogate, and deconstruct their stories in the hopes of reconstructing new meaning and understanding of the 
experiences (Connelly \& Clandinin, 1990, 2006; Clandinin \& Connelly, 1994; Lindsay \& Schwind, 2016).

\section{Historical Development of Narrative Inquiry}

The historical interest in narrative research began in the 1960s. Because narrative research generates a fundamental structure of human experience, the field of social science promoted its value with humans and their relations with themselves and their environment (Clandinin \& Connelly, 1994). Since the late 1980s, the study of narratives of human experience has become captivating to people across disciplines, particularly in the field of anthropology, history, and philosophy (Connelly \& Clandinin, 1990).

The development of Narrative Inquiry is nested in John Dewey's (1997/1938) pragmatic philosophy (Connelly \& Clandinin, 1990, 2006; Clandinin, Pushor, \& Orr, 2007; Lindsay \& Schwind, 2016). Two influential educational researchers, Connelly and Clandinin (1990) established their first publication on the methodology of Narrative Inquiry within the field of education. To ground the narrative view of experience, they drew on Dewey's two key criteria of experience, Continuity and Interactive. According to Dewey, the two criteria of experiences are enacted in a situation, which means that human experiences encompass the continuous interactions between people's internal thoughts and their physical, personal, professional, and social environment. Viewing the experience as a form of continuity, he believes that "our experiences are developed from other experiences, and that earlier experiences lead to further experiences" (Clandinin \& Connelly, 2000, p.2). The emphasis is on our experiences, as "it is a way of being and becoming" (J. K. Schwind, personal communication, March 9, 2017). His inspired view of experience as interactive illuminates the social dimension of the inquiries. For Dewey 
(1997/1938), experience is both social and personal, and narrative, as a methodology of inquiry, studies experience in context. Clandinin and Connelly (2000) agree that "people are individuals and need to be understood as such, but they cannot be understood only as individuals. They are always in relation, always in a social context" (p. 2). By studying narratives, we not only study the interpersonal world (existential condition) that is formed with others, but also the introspective world (internal condition) of the individual (Clandinin \& Connelly, 1994).

\section{Theoretical Framework of Narrative Inquiry}

The Deweyan understanding of experience underpins Connelly and Clandinin's theoretical framework of Narrative Inquiry. To them, it is the exploration of the ways in which humans experience the world, individually and socially, through storytelling (Connelly \& Clandinin, 1990; Clandinin \& Connelly, 1994). They define experience as the stories humans live and tell. In the process of telling the stories, they reaffirm and modify their lived stories, as well as create new ones. Dewey asserts his philosophical view of human experience as the phenomenon that shapes and is shaped by the individuals' social, institutional, and cultural experiences (as cited in Clandinin \& Rosiek, 2007). When conducting an inquiry using a pragmatic framework, our experiences reflect who we are as persons and as professionals based on the social interactions and relationships we form with others, inside and beyond a specific context (J. K. Schwind, personal communication, March 9, 2017). In the inquiry process, Connelly and Clandinin (2006) highlight the importance of engaging the narrative researcher in the participant's telling, living, retelling, and reliving their stories. It involves "a collaboration between the inquirer and the participant, over time, in a place or series of places, and in social 
interaction with milieus" (Clandinin \& Connelly, 2000, p. 20). By observing, listening, writing, and interpreting the lived story, alongside one another in text, the narratives become a reflection of the storied experience, which can validate and inform prospective knowledge (J. K. Schwind, personal communication, March 9, 2017).

\section{Three-Dimensional Space of Narrative Inquiry}

Connelly and Clandinin $(1990,2006)$ emphasize the need for narrative inquirers to think narratively while embracing and balancing the authenticity of Narrative Inquiry design. Grounding the Deweyan theory of experience as continuity, interaction, and situation, Connelly and Clandinin (2006) developed the tenets of three-dimensional space of Narrative Inquiry when exploring human experiences: temporality, sociality, and place. When studying the experience, narrative inquirers intend to understand the interplay of its three dimensions.

Temporality. Congruent with Dewey's first notion of experience, continuity, which acknowledges that every experience is developed, within a continuous cycle, from the past, through the present and influences the quality of future experiences. To Connelly and Clandinin (2006), temporality is conceptualized when an event or person is in temporal transition. It is embodied in the objects, places, and events that occur in our experiences, which connect to the past, present, and future. Throughout the inquiry process, we travel and discover alongside the participants as the telling stories uncover who they are, where they have been, and their prospective growth in the future. By attending to the temporality, as narrative inquirers, we also merge ourselves with the changes in our participants, as well as our own, internal and external environments that 
emerge over time. The inquiry quest encompasses the ongoing reflection, co-construction and reconstruction of newfound knowledge between the inquirer and the participant.

Sociality. Building on Dewey's second notion of experience, interactive, which indicates that all human experience is social and relational. This relational interaction, between the inquirer and participants, connects with Dewey's notion of experience between personal and social conditions. Personal conditions are identified as the feelings, thoughts, hopes, desires, and moral depositions of the participant and the narrative inquirer (Connelly \& Clandinin, 2006). The social conditions refer to the external factors, including social environment, people, community, and institutional policy that form the individuals' narratives. During the inquiry process, we aim to attend to personal and social conditions, to explore the multiple social influences at play in participants' own inner lives.

To Connelly and Clandinin (2006), narrative inquirers are invariably in an inquiry relationship with participants' lives. In the process of studying human experience, we become the co-participant while interacting socially with the participants over time in one or more places. In other words, by studying participants' stories of experience, the personal, social, and physical world of the inquirer and participants begin to form interconnections. Through collaboration, we negotiate our relationships, research purposes so as to transform the experiences of our internal and external worlds, while generating new knowledge and understanding that impact future experiences (Connelly \& Clandinin, 2006). This illuminates Dewey’s (1997/1938) philosophy of experience as being transactional with epistemological implication. He proposes that knowledge is constructed from experience. In Narrative Inquiry, knowledge is co-constructed between 
the inquirer and the participants, as the stories are told, shared, and interpreted throughout this reciprocal and relational inquiry.

Place. Drawing on Dewey's idea of situation in relation to human experience, Connelly and Clandinin (2006) conceptualize it as place. The dimension of place signifies "the specific concrete, physical, and topological boundaries of place" where the inquiry and events occur (Connelly \& Clandinin, 2006, p. 480-481). The qualities of place and the impact of places on lived and told experiences are important. As an inquiry proceeds temporally, we must acknowledge the power of physical place and its ability to evoke the ideas and feelings of the participants, which in turn, shape the way participants express their stories and how we interpret them (Clandinin, 2013).

These three-dimensional spaces provide a framework that holds the inquirer and the participants together as the stories of their lives unfold. These spaces are the criteria that allow narrative inquirers to think narratively, engage in framing the inquiry puzzle, and to compose the texts (field, interim, and research), as they enter the methodological landscape - Narrative Inquiry.

\section{Four Directions in the Study of Experience}

The Deweyan notion of continuity, interaction, and situation became an influential underpinning in Connelly and Clandinin's (2006) development of the threedimensional space in Narrative Inquiry. In addition to these three dimensions of experience, they identify the four directions of inquiry: inward and outward, backward and forward (Clandinin \& Connelly, 1994; Lindsay \& Schwind, 2016). By inward we focus on the internal conditions, such as feelings, hopes, values, and moral beliefs. Outward refers to the environmental situation and social conditions, and how they 
influence experience. Forward and backward are described as our internal temporality of experience through the past, present, and future (Clandinin \& Connelly, 1994).

Throughout the process of data collection and analysis, we navigate backward and forward in time while moving inward and outward to examine the personal-social conditions that shape human experience. By travelling across the four directions of Narrative Inquiry, Clandinin and Connelly (1994) believe that the inquirer and participants discover and co-construct new knowledge through this iterative process. During the exploration of the inquiry puzzle, the emerging narrative (from field text to interim text to research text) can identify not only who we are as persons and professionals, but also serve to inform the practice of disciplines and the community within which they are situated.

\section{The Three Levels of Justification}

In Narrative Inquiry, the inquirer aims to pursue a holistic exploration of participants' narratives with the fundamental value of relational and social experiences. There are three levels of justification that we use to justify the reasons for our research: the personal, the practical, and the social (Clandinin \& Connelly, 2000). We visit the three levels of justification at the outset of the inquiry to identify the reason for the particular phenomenon needs to be investigated using Narrative Inquiry. We then revisit the three levels of justification, during the stage of data analysis and interpretation, which ultimately responds to the question: "Why and to whom does it matter?" (Lindsay \& Schwind, 2016, p.15). This re-visiting of the levels of justification, also demonstrates Narrative Inquiry's dimension of temporality. 


\section{At the Outset of the Narrative Inquiry}

First level of justification: Personal. We, as inquirers, ask ourselves what brings us to the inquiry. The personal justification draws us to explore in detail the significance and concerns of the inquiry, and how the phenomenon of inquiry connects with our own narratives of experience, which in turn shape our Narrative Inquiry.

Second level of justification: Practical. The practical justification considers the significance of our inquiry by examining the existing research on the chosen phenomenon. This stage serves to identify the research gap and the scholarly literature that addresses the inquiry within the professional field (Lindsay \& Schwind, 2016).

Third level of justification: Social. The social justification requires us to look more deeply into the inquiry and consider the potential significance of our work to the greater society. This level of justification focuses on asking the questions "So what?" and "Who cares?" (Clandinin et al., 2007, p. 25).

\section{During the Stage of Data Analysis and Interpretation}

To Connelly and Clandinin (2006), Narrative Inquiry is a methodology to analyze the participants' stories as they express them through storytelling. In the process of data analysis, the inquirer hopes to interpret, analyze and so gain insights into the phenomenon under investigation. This process entails moving the field text (told stories) to interim text (reconstructed stories) and finally to research text (narratives of experience).

Stories are embedded in the field text and this text represents some aspect of reality (Clandinin \& Connelly, 2000). As field text may change during its telling and retelling, it requires the inquirer to read and reread the text several times to verify the 
chronological sequence of participants' stories. From this, the inquirer discovers narrative threads and patterns, as well as concerns located in participants' experiences within their overall social environment. The inquirer engages in navigating the four directions in the study (inward, outward, backward, and forward) to reflect upon the storied moment and identify how their personal-social conditions influence and correspond to the analysis, interpretation, and transformation of the stories.

Based on the field text, the inquirer constructs individual stories for each participant, creating the interim text (Clandinin, 2013). Interim text needs to be further negotiated and co-composed between the inquirer and the participants to ensure the text is honest and reflective of the told stories. After the participants confirm the accuracy of their stories, the inquirer continues to question the meaning and purpose of the study. They are cognizant that the three commonplaces of Narrative Inquiry account for their understanding of the complexity of experiences and its relevance to the inquiry puzzle (Clandinin, 2013). The inquirer analyzes the stories based on the three levels of justification (personal, practical, and social), to validate that the narratives address the inquiry puzzle and create final research text.

\section{How I Use the Three Levels of Justification in this Self-study}

During the process of analysis and interpretation in my self-study, moving from field text to research text, I, as a narrative inquirer, continue to stay in tune with the purpose and prominence of the inquiry. Living within the three commonplaces (temporality, sociality, and place) of Narrative Inquiry, I intend to develop a deeper understanding of the complexity of experiences pertinent to the research puzzle. I acknowledge that the field texts are "woven into the development of research texts" 
(Clandinin \& Connelly, 2000, p. 119). As I compose the research texts, I ensure that the created stories are analyzed using the three levels of justification (personal, practical, and social) (Clandinin et al, 2007), and that the narratives address the inquiry puzzle.

First level of justification: Personal. As a narrative inquirer, conducting a selfstudy, I need to first engage in the personal level of justification, justifying how my inquiry relates to the context of my own life experiences, and subsequently speak to the research puzzle. In chapter four, I construct six lived stories, also known as interim texts that identify myself as the participant and inquirer. As a participant, I tell my own stories that are related to and highlight my experiences as an immigrant-Early Childhood Educator working with immigrant children and their families. As an inquirer, I critically examine and interrogate these stories, within the four directions of Narrative Inquiry, by interjecting my wonders, observations, understandings, and feelings of the storied experiences. This interwoven dialogue style of presentation, demonstrates the multiple I's of Narrative Inquiry (Clandinin \& Connelly, 1998, 2000), where I am able to assume different perspectives based on the social roles I play.

Throughout the personal justification, I am aware of my "being" and "becoming" as a participant and co-participant within the inquiry process (Lindsay \& Schwind, 2016). As my inquirer-self interjects into my own stories, I am mindful of my inquirerparticipant role as I engage, back and forth, in the told stories based on my intimate connections with these stories. As a result, I am cognizant of the stories that I lived, and am able to reflect on and analyze them.

Second level of justification: Practical. As I engage myself in this process, I have to justify the significance of the inquiry within the professional field of early 
childhood education. In chapter five, I explore and analyze both the field text and interim text by presenting relevant literature to support and extend the existing knowledge of immigrant ECEs' experience of working with immigrant children and their families. By doing this, I gain deeper insights, ideas, and awareness of the meaning of my stories within the broader context of my own professional discipline (Clandinin et al., 2007). That is, I ask how does my inquiry into my experience of working with immigrant children and their families inform the greater profession of early childhood education. I also look at how the results of the inquiry may contribute to the larger body of literature, and the transferability of this work to the practice of other Early Childhood Educators.

Third level of justification: Social. In chapter six, I engage in the analytical process through the third level of social justification. I focus on asking the questions "So what?" and "Who cares?" (Clandinin et al., 2007, p. 25). By revisiting and examining the narrative patterns, I look at their implications and values to the larger social context, and reconstruct new knowledge by creating the final research text. The research text is formed to re-present my own stories and is meant to invite audiences, within and beyond the field of early childhood education, to reflect on and reconsider their thinking, understanding, doing, and relationships with others personally and professionally. It aims to engage the readers in looking into themselves, their "being", and exploring new possibilities of their "becoming" that contribute to potential personal, professional, and social changes in the future.

\section{Inquiry Design}

Self-study research. Self-study has become a prominent approach for Narrative Inquiry (Shields, Novak, Marshall, \& Yallop, 2011), especially when it allows inquirers 
to write about events and situations that connect their past and present and reveal the many layers of their own experiences. Bullough and Pinnergar (2001) point out that selfstudy has the capacity to provide insight and guidance, and can help readers learn from the experiences of others. In addition, self-study can inform one's practice and offer "insight and solution for public issues" in research (Bullough \& Pinnergar, 2001, p. 15).

ECEs' experience of working with immigrant children and their families has increasingly become an interest in the realm of early childhood education. Yet, immigrant ECEs' experience of working with immigrant children and their families have not been fully explored. As a result, my self-study, in which I examine, reflect on, and analyze my own experiences of working with immigrant children and their families as an immigrant, has the potential to enrich my own professional practice, as well as that of others, including the added value to the body of public research, discourse, and dialogue.

\section{Field Text Collection Process}

In this Arts-informed Narrative Inquiry (AINI) self-study, I retell and relive my lived stories through various artistic forms of narrative self-expression, such as journal writing, photography, metaphors, and drawing. Through the method of AINI, I use creative arts to describe and articulate my personal and professional experiences, as well as access my tacit knowing in the inquiry process (Schwind \& Lindsay, 2016). The collected and composed data, as Connelly and Clandinin (2006) describe, serves as field text (data) in Narrative Inquiry. In the field text collection process, I pay attention to the personal, historical, and social aspects of my inquiry while engaging in the four directions (backward, forward, inward, and outward) of Narrative Inquiry. 


\section{The Narrative Reflective Process}

Drawing on Connelly and Clandinin's (1990) Narrative Inquiry and Dewey’s (1997/1938) theory of experience, Schwind (2008) posited Narrative Reflective Process (NRP) as a creative self-expression tool, which supports critical self-reflection through storytelling, metaphor, drawing, creative writing and reflective dialogue. In this creative process, the inquirer and their participants are invited to express their storied experiences through reciprocal storytelling, followed by engaging in relevant metaphor selection, drawing, and creative writing. The images that emerge through this creative process often reflect the core quality of person-centered practices, the humanness of care (Schwind, 2008). Schwind subsequently used the metaphor of "self as instrument of care", symbolizing the service quality of her work as a nurse and a teacher (Schwind, Cameron, Franks, Graham, \& Robinson, 2012). The instrument metaphor gives voice to practitioners, a new language of sorts, for understanding themselves and those in their care (Schwind, 2016).

With the purpose of extracting a deeper meaning of the storied events, participants enter into reflective dialogue with each other, the inquirer and the extant literature, in order to extend their own understanding of the told experience (Schwind et al., 2012). This intra-interpersonal engagement invites individuals to discover their way of being and to reconstruct the experiences through storytelling, as well as to co-construct knowledge in relationship with each other. It allows the inquirer and the participants to view one another as human beings and to develop relational connections within and beyond the self at a humanistic level - humanness of care, especially with persons in their care in education and practice (Schwind, 2016). NRP is creative experiential 
learning approach that augments meaningful learning within personal-social-professional relationships through narratives, thus creating the possibility to understand, re-think, and re-construct professional practices.

In this self-study, I use Narrative Reflective Process as field text collection tool, to explore my own experiences as an Early Childhood Educator working with immigrant children and their families. Through this creative experiential approach (Schwind et al, 2014; Schwind, 2016), I engage in a series of self-expressive art activities (storytelling, metaphors, drawing, reflective journaling and creative writing) guided by my research supervisor, following the Narrative Reflective Process step-by-step. I begin by drawing a timeline of my life that denotes significant personal relationships and events under the line, while noting professional transitions above the line (Lindsay \& Schwind, 2016). Situating personal experiences below the line signifies the fundamental value of personal stories as they represent who I am, and what and how I think. It also demonstrates how these components are important attributes of my professional life. Following, I write three personal or professionally related short stories, review these stories and tease out narrative threads that run through them. From there, I draw two metaphoric images; one is a life-metaphor, and the other a "self-as-instrument of care" metaphor, denoting the professional self (Schwind et al., 2012; Schwind, 2016). During this process, I explore key narrative threads between the images. I share my stories and drawings with my supervisor, followed by individual reflective writing on what I am learning about myself. To tap into the sphere of imagination, I write myself a letter from my professional metaphor. This step further expands and refines my perspectives and understanding of who I am as a person and professional, and how these roles are interconnected. 
Using the creative self-expression of Narrative Reflective Process enables me to critically reflect on my lived experiences and reach my inner world that is often difficult to describe in words (Schwind, 2003). It brings about deeper self-awareness and openness about personal knowing, which are significant attributes of augmenting education, practice, and research (Schwind, 2016). By travelling through my personal (an immigrant) and professional (Early Childhood Educator) experiences temporally, from past to present, I discover new concepts in response to the inquiry puzzle and reveal how the internal and external conditions shape my future way of being. Throughout the narrative and reflective process, I am aware of the multiple voices that reflect my roles while entering the landscape of Narrative Inquiry. I honour the opportunity for the exploration of the multiple "I's" (Clandinin \& Connelly, 1998, 2000) by deconstructing, making meaning, and reconstructing the told stories, at different instances, as a first-born child, an immigrant, an ECE, and a researcher. Yet, in the writing of narrative, it is necessary for me to clearly identify the dominant voice in which I write as the inquirer (Connelly \& Clandinin, 1990).

\section{Ethical Considerations in Narrative Inquiry}

In this self-study, I focus on exploring and reflecting on my own experiences that inform my stated inquiry puzzle. Because my inquiry is a self-study, Ryerson University Research Ethics Board has determined that the usual ethics review was not warranted. (Appendix A).

To ensure the quality of the self-study, I, as a narrative inquirer, present how ethical considerations, including rigour and reflexivity are maintained in the inquiry. I 
also explicate the potential concerns of conducting a self-study as a form of Narrative Inquiry and make my awareness of these concerns transparent.

Rigour. Rigour in Narrative Inquiry involves narrative inquirers questioning, “What makes a good Narrative Inquiry?” (Clandinin \& Connelly, 2000, p. 185). To ensure rigour in the study of Narrative Inquiry, the narratives need to illustrate the exploration of temporality (the past and the present), and the interactions between the internal and the external conditions that contribute to the future experiences of the participants and inquirer, referred to as exploratory quality of narrative (Clandinin \& Connelly, 2000). Furthermore, narrative inquirers need to ensure the authenticity of the narratives, which means the interpretation and representation of the narratives must be accurate and truthful to the told stories shared by the participants. Clandinin and Connelly (2000) propose that the narratives should embrace an invitational component, which invites readers to reflect on their own experience and practices, and promote potential and positive change in their professional practice. As the inquirer and participants engage in the process of co-constructing, reflecting, and reconstructing their knowledge, the inquirer must ensure that each stage is exemplified and analyzed in a logical fashion, which reflects the plausibility of the narrative. The inquirer should ensure that the narratives achieve the criterion of adequacy, which appropriately captures the human experience, and addresses the inquiry puzzle.

Reflexivity. For narrative inquirers, it is important to engage in reflexivity throughout the entire research process. It encompasses the introspective reflection on the inquirer's personal and professional experiences related to the inquiry puzzle and how the participants' stories may affect their thoughts and feelings. The purpose of the reflective 
journals is for the inquirer to become aware and to make sense of their perspectives and emotional responses to the shared stories within the research process. As the nature of self-study heavily favours reflexivity, I engage in internal examination (inward movement) throughout the inquiry process, until I move the inquiry to the scrutiny of second and third levels of justification (outward moment).

\section{The Potential Concerns of Self-Study in Narrative Inquiry}

Connelly and Clandinin (1990) highlight that the value of Narrative Inquiry comes from its connection to lived experiences, especially because those experiences are extracted from both personal and social contexts in "relevant and meaningful ways" (p. 10). However, if those life experiences, as narrative data are untruthfully presented, the authenticity of the study becomes doubtful. As a narrativist conducting a self-study, a lack of authenticity is clearly a great concern for me. In the process of conducting a Narrative Inquiry self-study, I accept that my shared stories are open to examination, not only from myself, but also from others, which Clandinin and Connelly (2000) refer to as a way of "making meaning of experience" (p. 119). In other words, I need to be willing to accept others' critique, while simultaneously being analytical of my own narrative experiences.

As I enter the self-study through Narrative Inquiry, I retell and relive my stories of experience. I recognize that some of these stories may provoke despair and unpleasant emotions for me, which may place me in a vulnerable position. To mitigate this possibility, I create a safe physical and emotional space where I am able to stay in tune with my sense of balance. I also engage in journaling, as well as in regular reflective dialogue with my research mentor. 
Another concern that may affect the work of a narrative inquirer is the potential for self-indulgence. Being overly indulged into the narrative plot and my own role in the inquiry, without objectively examining the narratives, may place me at risk for, what Connelly and Clandinin (1990) call "the dangers of narcissism and solipsism" (p. 10). To minimize the potential for this risk, I constantly remain in the state of critical reflection. I ensure to make all inquiry decisions in a thoughtful and critical fashion, as well as remain committed to identifying which field texts I feature in this inquiry. While moving beyond the telling of the lived stories to making sense of the research stories through the multiple "I's", I stay alert to finding ways to form "I, the critic" (p. 10).

\section{Looking back ... Moving forward ...}

In this chapter, I reviewed the historical background and the theoretical underpinnings of Narrative Inquiry. In the next chapter, I present six stories of my life experiences and engage in the first level of analysis process of Narrative Inquiry (personal justification). 


\section{CHAPTER FOUR}

\section{Skipping Stones Across the Ocean:}

\section{Personal Justification}

In this chapter, I present six stories, in a chronological order, to denote the field texts (journals, drawings, photographs, and metaphors). In the six told stories, written in present tense, I tell and make sense of my lived experiences, as they are immediate, present, and relevant to my inquiry puzzle, How do I, as an Immigrant-Early Childhood Educator, Experience Working with Immigrant Children and their Families? I collected the field texts over the past several months. I view my storied experience as skipping stones across the ocean. While the stone (my lived experience) is skipping across the ocean, each and every experience leaves ripples that form my personal and professional thoughts and values, my identity. Central to Connelly and Clandinin's (2006) threedimensional space (temporality, sociality, and place) and the four directions (inward and outward, backward and forward) of Narrative Inquiry (Clandinin \& Connelly, 1994; Lindsay \& Schwind, 2016), I critically examine and reflect on the stories to explore my inquiry puzzle.

I illustrate the constructed stories of my own experience (interim text), after reading and rereading the field texts, which indicates my engagement in the first step of personal justification of Narrative Inquiry. Throughout the analytic process, the told personal stories are interjected with my responses as an inquirer-self. The inquirerparticipant interaction demonstrates the relational component (sociality) of the threedimensional space of Narrative Inquiry. To differentiate my voice as a first-born child, grandchild, immigrant, and an Early Childhood Educator, the teller of the story, I use the 
Apple Symbols font. I use the Times New Roman font to denote my inquirer voice. This form of presentation reflects the multiple "I's" of Narrative Inquiry (Clandinin \&

Connelly, 1998, 2000), which allow me to more deeply examine the chosen phenomenon from different perspectives.

\section{Story One: Learning from my Grandfather's Wisdom}

I am four years old, kneeling on a chair at the end of a long table in my grandfather's workroom, watching him prepare for his daily Chinese calligraphy practice. Every time I watch him, he looks very serious and is quieter than usual. He neatly organizes and places brushes, paint, ink, and paper in their own particular places.

Inquirer-Self: I wonder what he thought about as he meticulously placed each item on his worktable. What would have happened if brushes were not put in those chosen places? How would that have affected his calligraphy practice?

I especially enjoy seeing how he treats the ink. He gently pours the ink into a small stone dish and slowly moves the marble stick in circles. As he stirs the ink, I can hear the stone and marble rubbing against each other like the sound of a wind chime. The smell of the ink becomes more pungent. He approaches each piece delicately, as they all have their own contribution to his writing.

Inquirer-Self: Seeing my grandfather so reverently handle the ink and the brushes, I wonder how I display that reverence in my own life here in Canada. As an Early Childhood Educator, I work with immigrant children and their families. I most certainly hold them reverently in my presence and treat them with utmost care. He picks up a brush, dips it into the ink, pulls it out, and removes the excess by softly dabbing it onto another dish. As he writes each stroke of the character, he looks closely at the paper and keeps his arm straight. Grandfather does not teach me step-by-step what or how he writes during his practice. He just performs, and I silently observe.

Inquirer-Self: Through this simple performance-observation, my grandfather showed me the essence of engaging fully in each life event. I learned from him to treat everything and everyone with respect, because we are all interdependent. My 
grandfather's attentiveness to his calligraphy writing reflects my connections to my Chines cultural roots, and to the wisdom of the past generations. He is my role model, as I hope I am the role model for immigrant children I work with. I wonder what kind of life lessons they learned from their grandparents. Did they learn their own history and roots from them? Do the relationships with their grandparents influence how they experience their new home?

\section{Story Two: Lost in a Shopping Mall}

I am six years old. I am holding my mother's hand as we walk toward two tall automatic glass doors of a new mall, located near our apartment. While stepping into the foyer of the mall, I see an enormous chandelier made out of countless crystal balls, hanging from the ceiling. The mall is full of people. My mother begins her shopping in one of the stores. I, on the other hand, am intrigued by the variety of window displays and slowly walk away from her. She yells, 靄悀, 留起 呢度, 唔好走太遠呀! (Oi Ling, stay in the store, don't go far.) I nod, but, as soon as she turns around, I quickly walk out of the store. I turn into a long corridor lined with shops on both sides. I pass them one by one, starting from left to right. I look closely through the glass windows and gaze at all the lights, colours, mannequins, and other decorations in the displays.

Inquirer-Self: It seems my desire for exploration outweighed my fear. I was an explorer at heart. I was very engaged in the attractions that I discovered on my own. I was excited. My inquiring spirit did indeed begin at a young age. I recall how, as a teenager, I left home to immigrate to Canada. Moving to a new land, I became separated, not only from my country, but also from my family. I wonder how my mother felt when I was not around her in the mall? Was that the same feeling she had after I moved to Canada? Do other immigrants, who separate from their family, feel similarly?

I am not sure how long I am in the midst of this wonderment, but I know I should go back to mom. I walk around the store, yet she is nowhere to be found. My heart begins to beat rapidly. I keep mumbling "Mom... Where are you? Mom... Where are you?" I try to hold back my growing 
fear, but it is difficult. I wonder if I should ask someone to help me find my mother. Does anyone actually notice that I am lost and feeling unsafe? Do I look desperate enough to draw their attention? I am not crying, but I am scared that I will never go home and see my family again.

Inquirer-Self: It reminds me how I felt when I returned home for a visit, after a prolonged separation from my family. I was looking forward to recapturing the affection we shared prior to my migration. However, it faded. The sense of belonging to my family diminished. I felt like I was a misplaced calligraphy brush on my grandfather's worktable.

I hid my mixed feelings and suppressed them. I felt lost. I wonder if the immigrant children I work with, who appear quieter, are also trying to keep their emotions to themselves, holding back their tears and their fear?

\section{Story Three: Honouring the Confucian Value as the First Born Child - 仁 (Humanness)}

I am eight years old. The alarm goes off. It is 6 a.m. in Hong Kong. I have half an hour to do what I have to before waking up my brother. I am aware of my daily ritual, because I have been doing this since I was six. I make my bed, wash up, prepare breakfast for my brother and myself, pack our lunches and schoolbags, and make sure our school uniforms are neatly placed in the bathroom. Once all these tasks are accomplished, I wake my brother, wait for him to get ready, take breakfast with him, and we catch our school bus at 7 o'clock.

Inquirer-Self: These are a lot of responsibilities for an eight year-old child to take on. That must have been very difficult. I wonder if I had a choice to refuse the adult responsibilities. Are these the typical expectations of a first-born child in the Chinese culture? I wonder if other first-born children of different cultures are responsible for fulfilling the parental role to their younger siblings. The daily ritual reminds me of the procedural calligraphy practice of my grandfather. I feel that my life was structured in a linear pattern, which I learned to take one step at a time. 
I always sit beside or behind my brother to watch over his safety.

Inquirer-Self: It seems to me that I, as a young child, was often being an observer; from observing my grandfather practicing his calligraphy writing, to watching over my siblings. But who was there to watch over my safety and protect me?

I know that my parents expect me to be independent and I don't question why I am responsible for him.

Inquirer-Self: Like the moment I was lost in the mall, I held back my internal questions. I wonder if being the first-born child is to conform and fulfil parents' expectations. Was I happy the way I lived as the first-born child? I am aware that my interest in exploration could be challenged by the act of conformity. I wonder if it could ultimately create tension and retaliation. Would that be the reason why I decided to move away from my country and family?

My mother constantly reminds me, "You are the big sister. You need to look after your younger siblings. You have to model the concept of 1 二 (Humanness)." So, whenever I have a candy, I make sure my brother eats first. When he gets into trouble, I also take the blame. I have to protect my brother from being bullied and failing at school. When I have two portions of anything, I always give him the bigger one and I keep the smaller for myself. When my infant sister cries, I run to sooth her immediately. I bathe, feed and play with her. I continue into my adulthood to act upon the concept of 仁 (Humanness) - to protect and provide care for my siblings.

Inquirer-Self: The concept of 仁 (Humanness) encompasses the act of empathy, selflessness, motherhood, and protecting others from harm. Is it fair for a young child to cultivate all of these characteristics at such a young age? Why did my parents not let me be a child? I wonder if immigrant children, especially the firstborn, raised within the Chinese culture, are aware of the concept of 仁

(Humanness). Are these the qualities everyone strives to achieve regardless of the cultural background? 


\section{Story Four: Living with a Different Family}

I am seventeen years old. This is my first winter in Toronto. Although the sun is shining brightly, the ice-cold wind is so strong that it stings my face. With a couple of classmates, we walk and chat along the way to our respective bus stops after school. I am the only person taking bus fifty-seven, so I quickly run to the bus shelter to avoid the wind. When the bus finally arrives and I get on, I begin mentally listing the tasks I need to do when I reach home:

- Call my classmates to report my safety

- Clean the dishes that my cousins left in the sink

- Vacuum the kitchen floor

- $\quad$ Feed the dog

- Collect and fold the clothes in the laundry room

- Finish my homework before my aunt and uncle come home from work, so I can help them prepare dinner

Inquirer-Self: This is another daily ritual I had to adopt as a seventeen-year-old young adult. I was no longer the first-born, but rather the youngest in this family. It contradicted to the value of 仁 (Humanness) I learned from my own family. I was confused, but I did not question. Learning from my grandfather, I acknowledged the importance of showing respect and gratitude to my extended family, who offered me a place to live. It reminds me of the gratitude I had, and still do, for the opportunity that Canada gave me. These feelings of gratitude are very similar to those of the immigrant families I work with as an ECE.

I am taking off my shoes. The phone rings. It must be Annie calling me to make sure I am safe. The ringing stops and so does my heart. I am certain that someone else is in the house. But, who could it be? Am I in danger? Everyone else should be at work. I suddenly hear someone running up the stairs from the basement. A man's voice says, "Hey! Are you home? Come here." What a relief! It is my cousin. He looks upset. He sits on the couch in the living room, as I stand across from him. He yells, "I don't want to hear any of your friends calling this house. This is my house. Now that you live with us, you need to follow our rules. I just told your friend not to call again. You understand me? We are all older than you. You need to listen to what I say!" 
Inquirer-Self: Did my aunt and uncle teach my older cousin the concept of 仁 (Humanness)? I wonder if they treated him the same way he treated me. If this is the family dynamics and values that were rooted in the past generation, I wonder how it would affect the next generation and society as a whole.

The new rules in the new family reflected how I felt as an immigrant coming to Canada. I lived in a new country with new cultural values and norms. I needed to adapt to it. Reflecting on this experience, I remind myself again, that in my role as an ECE, I need to be aware of the barriers and issues that arise inside and beyond the classroom.

"Don't you dare mess up your life here, otherwise I will kick you out of this house and you'll have to sleep on the street." I nod, and turn around with tears streaming down my face.

Inquirer-Self: I must have felt very vulnerable because of the threat of eviction by my cousin. It draws to mind the feeling of insecurity I had being an immigrant. If I retaliated against the Canadian system, which I perceived to be reflected in my cousin's actions, would I be deported? I wonder what I would have done if I was evicted. What would I do if I saw similar injustices imposed upon the immigrant children and their families in my care? Would I take into account that their sense of insecurity and fear of deportation may hinder their ability to question my pedagogical practice in the classroom?

\section{Story Five: A Bruise on Mrs. Weareok}

I am sitting with Mrs. Weareok in the ECE staff room. She breaks down and explains how she got the bruise at the corner of her eye.

Inquirer-Self: Mrs. Weareok must have trusted me. I wonder if it was because we were both immigrants.

I can slightly see the colour of the bruise behind her sunglasses, as she recounts the incident. 
Inquirer-Self: I wonder if it was the bruise that she tried to disguise or something else, deeper. It takes me back to the moment when I was six years old, being lost in the mall, trying to hold back my tears and disguising my growing fear.

Thinking of the immigrant children and families I work with, I wonder what they hide behind the smiles they give me everyday. Would uncovering their true feelings reveal potentially unbearable pain and grief?

Although we cannot make eye contact, her pain and sadness tremble through her voice, as she says, "I know my husband did not mean to do it."

Inquirer-Self: I wonder if her justification of her husband's behaviour was to protect the safety of her family. Was she afraid of deportation too? Was she afraid of further violent outbursts from her husband? And seeing that her bruise is the result of intimate partner violence, what is the best way to proceed in such a situation?

She describes him as a loving, gentle, and caring husband and father before migrating to Canada. However, she noticed changes in his personality two months into their settlement. He often becomes very quiet, is easily agitated, and spends most of the time isolating himself in the public library.

Inquirer-Self: Mr. Weareok's settlement in Canada did not follow the trajectory he had hoped for. The public library seemed to be the only place where he could find comfort and grounding. For me, as new immigrant, I found comfort in school.

I wonder how Mr. Weareok's violent outbursts at home affect the wellbeing of his family unit, especially his children. If these family dynamics continued, how would that affect the family system of the future generation? 
Mrs. Weareok says, he constantly talks about not fitting in because of the language barrier, and not being able to find a job to sustain a stable life in Canada, and to support his parents who still live in their country of origin.

Inquirer-Self: I wonder if the need to provide supports for his families in both Canada and his home country was the cause of his outburst. He was the one supporting both families, but who was there to support him? He must have felt helpless. It makes me realize how I, as an immigrant myself, constantly struggle with balancing my role in a new country, while still wanting to perform the role I used to play in my home country. I do not have a sense of belonging in either place.

She takes off the sunglasses; I am more struck by the redness in her eyes than the bruise next to them. Over the next 10 minutes, all she does is cry. After a long pause in our conversation, Mrs. Weareok quietly mumbles, "We are ok. We will be ok. Our family will be ok." (HK, journal entry, April 26, 2017)

Inquirer-Self: I wonder if her story, like many immigrant stories, is an example of resilience. Or, is it a true intimate partner violence situation, that requires further looking into? Is her story a cry for help? I am left feeling helpless. How do I help this woman and her family?

\section{Story Six: Losing Touch with my Homeland}

[Wilson's grandmother] Are you Chinese?

[Me] Yes. I am.

[Wilson's grandmother] Do you speak Mandarin?

[Me] Yes. I speak a little.

Wilson's grandmother seems more relaxed and begins to speak with me in Mandarin.

[Wilson's grandmother] 你的中文都很不錯。你住在加拿大多久 ? (You speak Mandarin really well. How long have you been living in Canada?)

[Me] 已經十年多。你呢? (Over ten years. What about you?) 
Inquirer-Self: I was building a bond with Wilson's grandmother. I feel that our respective ethnic and cultural backgrounds and immigrant identity made her feel comfortable. I wonder if I, as an immigrant myself, become the trusting figure for the immigrant children and their families in my care, particularly for the Chinese community, as they might perceive me as someone who has similar cultural values.

[Wilson's grandmother] 已經有四年多。我來這裡是想照顧Wilson。我女兒和女婿要處理 他們的事業，我想幫助他們，所以我來到加拿大跟他們住。(It's been four years. I came to take care of Wilson. My daughter and son-in-law are both very busy with their business. I want to help them out, so I choose to come live with them in Canada.) [Me] 呀! 那你喜歡在加拿大生活嗎? (Ah! So how are you enjoying your life in Canada?) [Wilson's grandmother] 我的英文説得不好，所以我要常常跟著他們。他們可以為我翻 譯，要不然其他人都不會明白我。(I don't speak good English, so I have to always stay with my daughter and son-in-law. They are my translators; otherwise, no one will understand me.) Inquirer-Self: Language barrier made her communication with others very difficult. But, in my eyes, I see that communication is not merely based on verbal exchanges between human beings, but also involves their emotional and spiritual connections. This reminds me of the connection my grandfather had with his calligraphy and the connection I had with him. Our communication was formed by the attention I paid to his writing and his focus on the detail of his work. The back and forth exchange between our emotions and intellect looked like a dance. I became more understanding of my grandfather. I saw the similar way how immigrant children and non-immigrant children interacted in the classroom.

但在中國，我有好多朋友，我可以去不同的地方也沒問題。我可以依賴自己，不過 我現正反而是我女兒的負擔。 (But in China, I had my friends and I knew all the places. I was very independent. Now I feel like I am their burden.) 
Inquirer-Self: It seems to me that the immigration experience of Mr. Weareok and Wilson's grandmother altered who they were and shaped their way of being in Canada. This must be very isolating and lonely for them. As an immigrant myself, am I aware of the impact my immigration experience has had on me? Did I become a different person over the course of my time here in Canada? How has this affected both my immediate and extended families? Did those changes alter the way I interact with them?

這就是生活吧...有時候我們得到一些也可以失去一些 (This is life...Sometimes when you gain something; you lose something.)

Inquirer-Self: She describes life, as if it was a gamble. It involves winning and losing. In moving to Canada, she gained closeness with her family. I lost the precious moments I could have shared with mine. I feel like a "transplanted outsider" whose root, attached to my culture and family, was unearthed and relocated to an unfamiliar landscape, where I did not feel I belonged (Lindsay, Schwind, Papaconstantinou, Smye, \& Cross, 2016, p. 585). Wilson's grandmother lost her independence and the social networks she had established in China. I created my new networks in Canada, while navigating and negotiating within the new societal system on my own. Perhaps the age, among other factors, at the migration time, like the transplanted tree, makes a difference how we settle into the new land. It brings to my attention the different gains and losses of immigrant children and their families, and the uniqueness-sameness of each of our stories.

Wilson walks up to us.

[Wilson] (Speaking in English) Grandma, I don't want to leave yet?

[Wilson's grandmother] 但是我要回家者菜, 你的爸媽不知道我們去了哪。回家吧。 (But I have to go home and make dinner. Your mom and dad will wonder where we are. Let's go.) 
[Wilson] (Speaking in English) What about I phone mom and dad and tell them to pick me up from here after work, you just go home and cook?

[Wilson's grandmother] 我聽不懂你説甚麼, 説中文。(I don't understand what you are saying? Tell me in Chinese.)

[Wilson] 你跟我 phone 爸媽, 然後... (I phone mom and dad...You...)

Wilson looks frustrated, so I translate what Wilson said to his grandmother. She pauses.

[Wilson's grandmother] 我真的佷想可以跟他溝通 (I wish I could communicate with Wilson.)

Inquirer-Self: It is evident that language barrier was affecting her relationships inside and outside the family. I am aware how this language and now, cultural barrier, between Wilson and his grandmother was fracturing their grandparentchild relationship. Their relationship is quite the opposite of the relationship I had with my grandfather. I wonder if their relationship would affect Wilson's perspectives on his ethnic and cultural identity as a Chinese boy. Will he feel resentful towards his immigrant grandmother? I see her, as a "transplanted outsider" trying to survive not only in a new country, but also in her family. I reflect on my own immigrant story. I too am very familiar with the feeling of being an outcast, a transplanted tree.

\section{Looking back ... Moving forward ...}

In this chapter, I engaged in the first level of analysis, the personal justification. While revisiting my personal (first-born child, grandchild, and immigrant) and professional (Early Childhood Educator) stories, I consistently engaged in the threedimensional space: sociality, temporality and place (Connelly \& Clandinin, 2006), as well as the four directions (inward and outward, backward and forward) of Narrative Inquiry (Clandinin \& Connelly, 1994; Lindsay \& Schwind, 2016). 
Throughout the storyteller-inquirer interactions (sociality), I traveled backward and forward, from childhood, grand-childhood to my time of being an immigrant and Early Childhood Educator, as well as in my role as a storyteller-inquirer (temporality), between Hong Kong and Canada (place). By interjecting my stories with my inquirer voice, I am able to reveal my internal (feelings, perspectives, and moral dispositions) and external conditions (social relationships, and environment). The way that I engage in the stories illustrates the exploratory quality of Narrative Inquiry (Clandinin \& Connelly, 2000).

In the next chapter, I engage in the practical level of justification of Narrative Inquiry. I integrate relevant literature to analyze and interpret my inquiry puzzle within the broader context of my profession of Early Childhood Education. 


\section{CHAPTER FIVE}

\section{Data Analysis and Interpretation}

\section{Practical Justification}

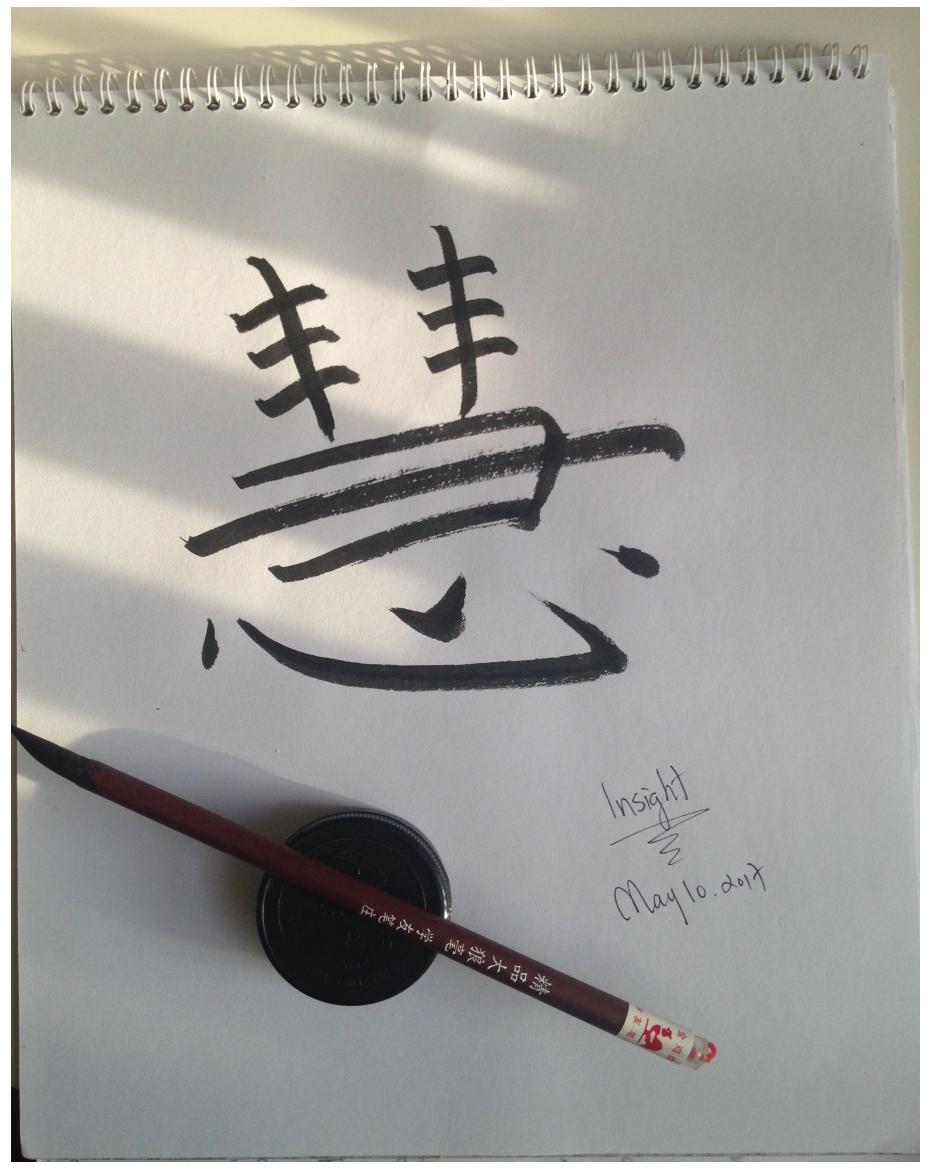

Figure 1. Insight.

In this chapter, I move into the second level of analysis of Narrative Inquiry, the practical justification. To complete this level, I continue to critically interrogate the told stories, while simultaneously integrating the existing scholarly literature to make meaning of them within the professional context of Early Childhood Education.

\section{Second Level of Analysis: Practical Justification}

After reading and rereading the interactions between my storyteller-self (telling of stories) and my inquirer-self (interjections of wonderment) in chapter four, I am now 
entering into the second level of analysis. At this stage, my storyteller-voice diminishes and my inquirer-voice becomes more dominant. During the analytical process, I continue to delve into the told stories and scrutinize them within the broader context of the Early Childhood Education profession. I use the theoretical lens of Narrative Inquiry to critically analyze the emerging narrative patterns from the interim text (the told stories) and integrate scholarly literature to deepen my understanding of them.

\section{Theoretical Framework: Three-Dimensional Space of Narrative Inquiry}

In this inquiry, I use the three-dimensional space of Narrative Inquiry, as the theoretical lens, which guides my conceptualization and analysis of experience as told in the six stories. Grounding the Deweyan philosophy (1997) of human experience as continuity, interaction, and situation, Connelly and Clandinin's (2006) development of the three-dimensional space of Narrative Inquiry allows narrative inquirers to deepen our understanding of the possible meaning of human experience. Guided by the tenets of the three-dimensional space of Narrative Inquiry, I critically examine my personalprofessional experiences temporally (past, present and future), socially (in relationship with myself, others and society), and across different places (physical locations where events occurred). Through this process, I gain an in-depth knowing of who I am and what I do, as a person (first-born child, grandchild, immigrant) and a professional (Early Childhood Educator). With the personal-professional knowing examined in this way, I create more informed choices for my future actions in my personal and professional life.

The three-dimensional space of Narrative Inquiry is demonstrated throughout the entire process of the inquiry. As I move backward and forward, inward and outward, in the field text collection process and the personal level of justification, I continue to 
analyze the told stories, using the theoretical lens, to complete the practical justification, as well as the social justification in chapter six. In other words, to gain a more expanded view of the storied experiences, as an inquirer-self, I now step back from the told stories and analyze them within the context of the professional field of Early Childhood Education (Lindsay \& Schwind, 2016). In this analytical process, I remain attentive to the temporality (temporal situation), sociality (my relationships with self and others), and place (environment), while drawing on relevant literature to deepen my understanding of the inquiry puzzle.

\section{Narrative Patterns}

As I read and reread my told stories, three emerging narrative patterns are unfolded within and across these stories: challenges in a new home, a sense of belonging, and perseverance. Each of these patterns is comprised of two narrative threads, which are identified below.

As I analyze the narrative patterns, along with the existing literature, my experiences as an immigrant and an Early Childhood Educator resonate with those in the studies. Here I use the pronoun "we" to refer to my shared immigration experiences and to how my personal and professional identities are inseparable from my told stories.

\section{Challenges in a New Home}

Immigrants often migrate to a new country with the intent of finding a better life. We begin such a journey with hopes, excitement, expectations, as well as fear and uncertainty. As we try to immerse ourselves in the receiving country, our new home, we encounter numerous challenges in the settlement process. Upon closer examination of my 
told stories, I am aware that within this narrative pattern are imbedded two prominent narrative threads: language barrier and navigation of cultural differences.

Language barrier. The inability to communicate with others and express our thoughts in English is often the most challenging experience as new immigrants. It prohibits us from adapting and participating fully and confidently in our new home. Although research suggests that immigrant children are subjected to high risk of developmental delay and poor academic performance due to language barrier (Karoly \& Gonzalez, 2011), it is particularly challenging for immigrant adults and elders, whose lives were well established socially and economically in their country of origin. For example, Mr. Weareok (Story Five) was a chemical engineer, and Wilson's grandmother (Story Six), was an independent retiree, but missing her children and grandchild here in Canada. In order to restart their new life, they had to give up what they had (family, friends, neighbours, career, comfort) from their home country. With limited English skills, it now becomes very difficult for them to rebuild what they left behind and to be fully integrated in the new environment, without experiencing the feelings of frustration and loneliness.

Frustration. Looking at Mrs. Weareok's story, she shares that her husband's low English proficiency made him feel isolated, and that it limited his opportunity to obtain a job. Being the breadwinner for the family, and his parents in his country of origin, he faced tremendous pressure to secure stable employment. Surrounding the internal and external stressors, his violent outburst towards Mrs. Weareok may have come from this high level of frustration. Research reveals transitions in one's life, experienced during the settlement process, can have a negative effect on spousal relationships (Guruge et al., 
2010). As immigrants hurdle through resettlement adversities, inadequate social support becomes one of the major catalysts for spousal violence (Guruge et al., 2010; Hyman, Guruge, \& Mason, 2008).

Hearing Mrs. Weareok's experience prompted me to educate myself on the topic of intimate partner violence (IPV) (World Health Organization, 2012), and how to better support families in such situations. Literature suggests that immigrant women of intimate partner violence suffer from various forms of abuse (Guruge, Roche, \& Catallo, 2012; Canadian Council for Refugees, n.d.). Guruge et al. (2012) reveal that many immigrant women of Iranian and Tamil communities experienced psychological (intimidation, insult), physical (kicking, hitting), and sexual abuse (unwanted sexual intercourse) within the Canadian context. They point out that intimate partner violence affects women's mental and physical health as a result of feeling depressed, anxious, and experiencing suicidal thoughts (Stewart, Gagnon, Merry, \& Dennis, 2012). In addition, immigration and sponsorship processes often place one partner in a position of power over the other. Such power imbalances make the victim of the abuse more vulnerable (Canadian Council for Refugees, n.d.).

It is important for Early Childhood Educators to learn how to recognize intimate partner violence, as any violence in the home negatively impacts the children. Conducting on-going observation and assessment of the family dynamics and interactions allows us to discover the signs and symptoms of potential abuse. Having competent professional skills is key to form realistic support and strategies to help immigrant spouses who experience spousal abuse. As we approach to support the family, we must listen to their concerns compassionately. More importantly, we must remain culturally 
sensitive to the families' understanding of the concept of intimate partner violence based on their cultural values, morals, and beliefs. Making available community resources (English classes, employment support, social clubs) that help ease the post-migration process, can mitigate family stress and potential violence inside the home.

As mentioned above, this is particularly relevant for the field of Early Childhood Education. A number of studies find an association between spousal violence against women and negative mental, social and emotional well-being of children, including anxiety, depression, and poor school performance (Heise \& Garcia-Moreno, 2002; Kishor \& Johnson, 2004). Children who are victims, or who witness violence at home, may display their stress in the classroom by exhibiting disinterest in learning, externalizing and internalizing behaviours, and other symptoms. To gain better understanding of how to support those in our care, who may be victims of abuse, we must first educate ourselves, pay close attention to children and families' changes in behaviours, and then be available to respectfully listen to their stories.

As an Early Childhood Educator, who is also an immigrant, I acknowledge that immigration is a stressful situation, especially for the older generation. Despite the joy of reunion with her family, Wilson's grandmother's relationship with him became frustrating: her lack of English speaking skills, and his lack of Chinese speaking skills. I also recognize her embarrassment of being a "burden" on her family, as she had to rely heavily on them to navigate in the Canadian society. Living with my extended family, I am familiar with the feeling of being a "burden" on them. Although I feel their treatment of me (Story Four) exhibited a form of control, I also know that they also made sacrifices to look after me. 
Reading the story of Wilson's grandmother, who used to be an independent mother and grandmother living in China, she had a happy social and stress-free life. After moving to Canada, she became a dependent mother-grandmother figure, who now has a limited social life and difficulty navigating the new culture. She sees herself as a burden on her family, which she tries to minimize by keeping up with the caretaking role. In a semi-structured interview study with twenty-nine Chinese immigrant grandparents, exploring their caregiving of their grandchildren, reveals their sadness for playing the role of a parent, rather than a grandparent, and feeling stressed about fulfilling their adult children's expectations by taking care of the household (Xie \& Xia, 2011). By taking on full-time responsibility of looking after Wilson and helping with the home, his grandmother had less time to integrate into her new country, which heightens her sense of isolation.

This reminds me of my role as a first-born child carrying the responsibility to look after my siblings, doing chores, and protecting them from harm (Story Two). I felt pressured and had wished that I was given time to play and learn with peers. In the article examining the findings of a study that looks at the experiences of immigrant girls, who provide care for their younger siblings, shows that their caregiving practice offers unpaid emotional and physical labour to the family (Lee \& Pacini-Ketchabaw, 2011). Looking at the phenomenon within a transnational context, immigrant girls help their families acquire social capital and economic advancement, while they take on the parental role in assisting their younger siblings to develop complex cultural knowledge. For this reason, early years professionals need to be mindful of the position of the oldest immigrant children, especially girls, in their family, and they need to look closely at the impact of 
their caregiving identities on their perception of gender roles and how they feel about their daily care to their siblings. We need to be aware of both the positive and the negative effects of the role of eldest children on their learning and overall development, and ensure that we are well prepared to provide necessary care and support for them.

Loneliness. A number of studies highlight that loneliness is common among adult and older immigrants (Kim, 1999; Madhavi, Guruge, Schwind, \& Martin, 2014; Schwind, Fredericks, Metersky, \& Porzuczek, 2016). The absence of close family and spousal relationships, or social connections, can result in loneliness (Weiss, 1973). Migrating to Canada as a teenager, I left my close family and friends behind. I lost intimate contact with the people that I trust and with whom I have an emotional bond. Looking back at Mrs. Weareok's story, her husband's violent outburst and self-isolation exemplify his inability to provide emotional, mental, and physical supports for his family. This, in turn, fractured the family relationships, and lead to the isolation and loneliness of the entire family (Madhavi et al., 2014). In this case, as educators, we need to be alert to the post-migration challenges that impair family dynamics and place children in harm.

In my inquiry, loneliness experienced by immigrant adults and older generations is evident within the told stories. Looking at this experience from the field of Early Childhood Education, there is limited research investigating specifically the impact of loneliness on immigrant children's integration within the school setting. While Kirova (2001) suggests the use of non-verbal communication and the arrangement of the physical space are effective strategies to eliminate children's isolation and loneliness, educators should also recognize that loneliness differs between individuals. She also argues that it is difficult for immigrant children and families to verbally articulate such 
social and emotional concepts due to the lack of English speaking skills. Therefore, Early Childhood Educators could engage them in exploring their settlement experiences through creative self-expression. For example, the Narrative Reflective Process (Schwind, 2008), involving creative activities (metaphor, drawing, creating collages) can be helpful in bringing forward feelings and thoughts "unreachable by words" (Schwind, 2003, p. 25). In this way, we could gain deeper understanding of their unique experiences and so become better equipped to create and implement flexible pedagogical practices that fit individual child's emotional and social needs within the classroom.

The navigation of cultural differences. In addition to overcoming our limited English proficiency, as immigrants, we are faced with challenges of not only adjusting to and understanding the cultural beliefs and practices in the host country, but also expressing our own cultural values to others. Cultural values encompass a set of socially constructed customs, beliefs, rituals, behaviours, social rules, and interpersonal relationships that are shared among a group of people within a specific place or setting (Sodowsky, Kwan, \& Pannu, 1995). In many cases, during the process of navigating between the different cultures, immigrants are confronted by these differences and experience internal conflicts.

Internal conflict. Growing up in a family that is influenced by Confucianism, as a first-born child (Story Two), I was raised to honour the concept of 仁 (Humanness) to practice the act of compassion, selflessness, and sincere care for the youngsters within family and others in society. It brings me back to my relationship with Wilson's grandmother and my memory of my grandfather. The cultural practices in harmony and 
unity we all share bring us closer together, but it also creates internal conflict when these are confronted by different cultural practices.

Being the eldest sibling performing the concept of 仁 (Humanness) within my family, I developed the characteristics of a care provider who is willing to sacrifice herself. On the other hand, my extended family here in Canada operated within a different family and cultural structure, involving power and control. As I share in Story Four, I was conflicted by these dissimilarities and felt distress while trying to rationalize the two families' practices. Working in the classroom, I notice that some immigrant children appear very anxious and frightened during certain classroom routines, particularly circle time. It may be that they feel unsafe to open up to others within a new environment. With the language barrier and unfamiliarity with such social activities and the new environment, it may become very difficult for these children to engage, which can potentially affect their social awareness and adaptation to the classroom.

Educators report feeling ill-equipped to understand and accommodate immigrant children's values, as the content of diversity taught in pre-service training is primarily theory-focused, and they find it challenging to apply it in a practical situation (Goodwin, 2002). Consequently, several researchers advise that Early Childhood Educators' recognition of their own assumptions and awareness of cultural differences are keys to strengthening their professional growth, while working with the immigrant population (Buchori \& Dobinson, 2015; Chen et al., 2009; Han \& Thomas, 2010). I believe, it is especially important for my Early Childhood Educator colleagues, who, like me are immigrants. This is exactly what I am doing by undertaking this self-study. I must be honest about my rooted cultural values and open to be confronted by the engagement 
with individuals who hold different beliefs. Seah (2005) indicates that immigrant educators carry with them certain teaching approaches from their country of origin. For example, they may present themselves as knowledge holders, and demand the utmost respect from their students. With that, it becomes challenging for them to apply Western philosophy, which holds that educators should earn children's respect. As a result, these Early Childhood Educators may feel conflicted or retaliate, affecting their sensitivity to children's needs and ability to foster their learning. In this case, we must be aware of our socially constructed routines, pedagogical practices, attitudes, teaching philosophy, and the use of language in the classroom. We must question how the dominant cultural values could intensify the challenges for new immigrant children and their families.

\section{A Sense of Belonging}

For new immigrants, the feeling of belonging is associated with the need for acceptance and to be treated as meaningful beings within the community. The legal title, immigrant, is intended to give us the right to obtain citizenship and access immigration and settlement resources; such as English Learning classes, employment counselling, and other integration programs (Citizenship and Immigration Canada, 2010). However, beneath that well-meaning title we are individuals who constantly feel like outsiders and struggle to find a place where we truly belong.

We are the outsiders. Immigrants face a steep learning curve in terms of learning a new language, new culture, and simple social norms, all of which further reinforce their identity as outsiders. Schwind uses the metaphor of a "transplanted outsider" whose roots, deeply connect to culture and family, are removed from their native soil and replanted into a strange new landscape, where they do not belong (Lindsay et al., 2016, p. 
585). The transplanted plant struggles to survive and strives to adapt to the new environment. The period of adjustment becomes overwhelming, at times feeling like "a tumble weed that blows in the wind" wondering where it belongs (J. K. Schwind, personal communication, August 2, 2017).

Mr. Weareok's violent outburst may be the result of feeling emotionally imbalanced due to the stress from the language barrier and not fitting in. To the Weareok family, immigration also changed their family dynamics and in turn created conflict amongst them. Research reveals that individuals require internal and/or external resources to go through life events (Xie \& Xia, 2011). For example, Mrs. Weareok's decision to share her story with me may have helped her alleviate some of her personal stress.

Research shows that immigrants' strong social connection to their family and community can mitigate social loneliness (Weiss, 1973). However, it is also argued that individuals can experience the feeling of loneliness even when they are surrounded by a crowd, or being alone without feeling lonely (Madhavi et al., 2014). It is the qualities of the social relationships developed between people that makes them feel validated and accepted as social beings. In this way, their 仁 humanness is respected. Thinking back to the connections I had with Mrs. Weareok (Story Five) and Wilson's grandmother (Story Six), I feel that Early Childhood Educators play an important role in creating an environment for and relationships with immigrant families to increase their sense of social and emotional belonging. It is critical that we acknowledge that immigrant families' sense of belonging to their own family, community, people, and country may directly influence their children's sense of belonging and well-being, as they are 
interconnected. Observing how my grandfather used the calligraphy items as a collective set (Story One), depicting the power of unity, I have grown to value community and meaningful social relationships, which can foster the sense of belonging for the children and families in my care.

Being an Early Childhood Educator, who is also an immigrant, I recognize that the fundamental element of emotional belonging is formed on the basis of trust. My relationship with immigrant families seems often to be facilitated by trust. In fact, more so than with my colleagues who are non-immigrants. As a result, many of my colleagues would primarily depend on me to communicate with the immigrant families and children, addressing their concerns. In fact, they expect me to be the only one to engage with the immigrant population. My professional knowledge, practices, and identity as an educator are rather overshadowed by my immigration identity and cultural compatibility with other immigrants. After working hard to obtain the Canadian knowledge and credentials in the Early Childhood Education profession, I feel that it is not fully acknowledged and utilized. As visible minorities, immigrant educators often share their sense of social isolation and the dismissiveness from their Canadian colleagues in their workplace (Myles et al., 2006; Schmidt, 2010). Regardless of where I go or whom I meet or live with, my identity as an outsider remains.

Despite experiencing the trial of searching for my own sense of belonging to my cultural and professional identities, families, home country, and Canada, I recognize my strong commitment to support immigrant children and their families in nurturing their sense of inclusion and acceptance. Childcare centers play an instrumental role in the integration of immigrant children because it is often the first social and cultural 
institution that they enter, outside of the home. It is evident that children with a higher sense of belonging may have fewer psychological issues and social problems, and have greater possibility to show optimal cognitive and psychosocial functioning (Chiu, Pong, Mori, \& Chow, 2012). Early Childhood Educators should always strive to explore what belonging means to the people they care for and examine how they can create an effective environment where mutual respect, empathy, and inclusion are demonstrated.

Where do we belong. As a child, watching my grandfather practice his calligraphy and actively modeling the Confucian concept of 仁 (Humanness), I was instilled with Chinese values, morals, and beliefs. My home country is the soil, where I felt comfortable to grow, as I shared the same customs, values, language, mannerism, and traditions with the people around me. Speaking to Wilson's grandmother, I suddenly felt that comfort again, and I believe she felt the same. In a study, examining immigrant teachers who teach children of recent immigrants found that teachers, who are themselves immigrants, are situated in the perfect position to bridge the cultural and linguistic worlds of school and home for children and families of the same ethnic communities (Adair, Tobin, \& Arzubiaga, 2012).

Immigrant educators indicate that they feel a strong connection with the children and families because they can easily articulate and share their concerns and desires for their children's learning. To ensure immigrant children are fully supported by the entire teaching team, not only immigrant educators, the centre should create a mentoring system for non-immigrant educators. Connecting immigrant and non-immigrant educators to learn from and with each other is integral to fostering a supportive community and children's learning. 
Similar to Mr. Weareok and Wilson's grandmother, we need to temporarily put our cultural roots and identities aside to acculturate to the Canadian society. We need to relearn a new language, norms and culture, and establish the Canadian experience and skills, to adjust to our new home. Recent research assessing the relation between immigrants' acculturations with their sense of belonging shows that acculturation experience is highly associated with immigrants' sense of belonging to Canada and their home country (Hou, Schellenberg, \& Berry, 2016). They highlight the essence of immigrants' maintenance of their culture identities and values to their overall well-being, engagement with the receiving society, and strong attachment to their cultural heritage, which in turn heightens their contribution to Canada.

Wilson's grandmother, who struggles with language barrier and social integration, has the opportunity to perform her role as a grandparent (Xie \& Xia, 2011). This may contribute to her sense of belonging. For example, she uses the "mutual aid model" adopted by Chinese families to fulfil her role, which means that family members are encouraged to be interdependent and provide mutual care for each other (p. 385). This model is often manifested in the case of grandparents offering care for their grandchildren, especially when they are still young. This reflects the value of 1 仁 (Humanness) that I embraced by looking after my younger siblings. Living with my extended family, on the other hand, inhibited me from maintaining my cultural practices and beliefs, which made me feel that what was rooted within me was unwanted and unimportant. Although Wilson's grandmother and I were both challenged by integration difficulties, her opportunity to retain the "mutual aid model," within her family, may 
foster her sense of belonging to her family and enhance her acculturation experience. For me, I belonged neither to Canada, nor to my extended family.

After I moved to Canada, I separated, not only from my country of origin, but also from my family of origin. The longer we were apart, the more I felt that my sense of belonging to my roots - my homeland and family - was fading. This may be related to Mr. Weareok's isolation from his family and society. The further he kept himself away from his social environment, the more likely his sense of belonging to either his new or his old country was diminishing.

As I returned home for a visit, after a prolonged separation, I experienced culture shock in my country of origin, and I struggled in speaking my mother tongue with my family. I felt lost and frustrated. It draws me to think about the communication conflict between Wilson and his grandmother (Story Six). Research argues that language barrier is a common issue affecting immigrant parent-child and grandparent-child relationships (Costigan \& Dokis, 2006). The difference in language proficiency levels indicates their acculturation differences and it is most significant during early adolescence. While their parents or grandparents are having difficulties engaging in their social environments, children increasingly participate in social activities independently. Over time, their communication gap widens and may lead to greater strain on their communication and their relationship. (Costigan \& Dokis, 2006; Foner \& Dreby, 2011).

It is believed that immigration is a life event that brings about changes in immigrants' lives and has a lasting impact on their social surroundings and family relationships (Xie \& Xia, 2011). This is especially true for those changes that result in disparities. In my case, the changes induced stress in the family system and created 
distance between us. The challenges I experience, as an immigrant in Canada remained, but this time they occurred within a place and with the people I used to feel that I belonged to. My sense of belonging further deteriorated, as it evolved over time and within different contexts. Research reveals that the formation of transnational families, whose family members live apart, creates strain within the family and resentment on behalf of young children upon reunification (Foner \& Dreby, 2011). However, there is a lack of research exploring the effects on the transnational family dynamics for young immigrant adults, who migrate to another country, while leaving behind their family of origin.

Acculturation differences between parents and children or grandparents and grandchildren are associated with children's level of well-being and mental health (Bacallao \& Smokowski, 2007; Costigan \& Dokis, 2006; Foner \& Dreby, 2011), including lower social competence and life satisfaction, which intensifies their anxiety, low self-esteem, and depression. Early Childhood Educators must recognize the acculturation differences of immigrant children and their families and their negative effects on children's learning and adaption in the classroom. It is important to pay close attention to the communication dynamics between the children and their families, and examine the changes in their roles, attitudes, and behaviours, which may consequently damage their relationships and the acculturation experiences.

\section{Perseverance}

Despite dealing with the on-going integration challenges (language barrier, the navigation of cultural differences, social and economic instability), which affect family relationships and emotional well-being (frustration, loneliness, internal conflicts, sense of 
belonging), as immigrants, we continue to show our perseverance, determination, and optimism to work through the hardships and build a prosperous future for ourselves and our families. In the process of achieving our commitment, the persistent stress and difficulties somehow make us more attuned to our need to survive and prove ourselves in the new country.

The need to survive. As new immigrants leaving our native land to invest in the prospect of a better life for our families, is often a significant motivator to persevere. Many immigrants wish to quickly obtain employment, and hope to maintain the career they had from their country of origin. Research indicates that immigrants feel disadvantaged and devalued in the labour market because of the language barrier, lack of social networks, and their skills and credentials not being recognized (Beaman, 2012; Sanders, Nee, \& Sernau, 2002). For example, Mr. Weareok (Story Five) was as a senior chemical engineer in his home country. He thought that he could continue to work, or even be promoted to a higher position in the new country. However, due to the language barrier, lack of social networks, and the difficulty of meeting the professional standards required in Canada, his previous education and experiences were discounted. This is similar to Wilson's grandmother's story (Story Six). Prior to her migration, she spent most of her life working hard to build her reputation, independence, and social and economic status in China. After coming to Canada, her previous success became irrelevant.

Despite their accomplishments not transferring to Canada, Mr. Weareok and Wilson's grandmother both decided to remain. The future of their families was their primary motivator to persist. However, Mrs. Weareok's persistence to survive appears to 
be more prominent than her husband's. She continues to think positively, regardless of the abuse that seems to transpire in her home. Her mental strength demonstrates her desire to survive for her child, while Wilson's grandmother stays to help look after her grandson and so to be closer to her family.

In my Story Two, I am a young child who loves to explore. Migrating to Canada fulfilled my own interest in exploration for new opportunities in life. During my experience living with my extended family (Story Four), however, I had to follow their house rules. I was made to believe their rules were those of Canada. Consequently, I became afraid of deportation if I retaliated. Although I was constantly living under control and fear, I knew I needed to withstand the situation in order to survive in Canada. Similar to Mrs. Weareok, who was dealing with physical violence at home, I dealt with emotional violence in order to survive and stay in my adoptive country.

Research suggests that immigrants are likely to be exploited due to their lack of knowledge of their rights and their willingness to lose their rights, for the sake of their family (Vogel, 2009). "Immigrants will do anything because they're here, they are here for their family and their future. They're willing." (Bean \& Bell-Rose, 2003, p. 207). As I listened to Mrs. Weareok's stories, I recalled how I felt living with my extended family. I knew that my rights were violated, just as Mrs. Weareok's was aware that her husband's violent outburst was unacceptable. As Early Childhood Educators, we need to remain non-judgemental and culturally sensitive to families' stories, and recognize how their immigration status may affect their decisions in dealing with family conflicts or social injustices, and how these have impact on children's well-being. We must gain a better understanding of the current immigration policies, inform immigrant families of their 
rights, and work together to examine ways of overcoming each systemic barrier (labour market, legal, education, housing, and healthcare).

When immigrants become the victims of maltreatment, poverty, or injustice, they normally disguise the situation to protect the safety, legal status, and the reputation of the family (Card \& Raphael, 2013). It is important that we, as Early Childhood Educators, recognize that their survival instinct may centre on their fear of deportation and lack of legal knowledge. Research shows that some immigrant children feel that their parents, who do not speak sufficient English, cannot provide for or protect them in the world outside their home (Clauss-Ehlers \& Weist, 2004). In this case, children may believe that they must protect their parents, rather than being protected by them, leading immigrant children to become "parentified" at an early age (Clauss-Ehler \& Weist, 2004, p. 105). Based on my professional experience, children are often advised by their families not to disclose their adversities and not to trust others. The impact of such advice on children's perception of others may be carried into the classroom, where it can interfere with their social development and their ability to maintain interpersonal relationships (Massachusetts Advocates for Children, 2005). Creating an environment where children are allowed to be children, without feeling pressured to resolve adult issues, increases their trust in others, as well as in their own ability to make social connections, and thus to thrive in their new home.

The need to prove themselves. To ensure that their children and family can flourish in the new country, immigrants need to constantly prove themselves as competent and hard working new members in the society. Due to their lack of English proficiency and other disadvantages (limited employment, discrimination, cultural 
difference), immigrants are required to put extra effort to integrate and prove that they are not burdens to their new country (Tastsoglou \& Jaya, 2011). Mine, and Wilson's grandmother's stories, demonstrate how we need to prove ourselves not only to the Canadian society, but also to our families, because we are afraid to disappoint them.

Since I arrived to Canada, I began to think about how I could contribute to the new country. I did not want to be a burden for my new home. Remembering the moment when I learned about gratitude from my grandfather, I was eager to show my appreciation to Canada by being a productive member of its society. I studied extra hard at school, tolerated discrimination and maltreatment from my extended family. I wanted to show others that I was a capable and good immigrant.

For Wilson's grandmother, she also needed to work hard to counter-balance her guilt for being a burden on her family. She had to prove that she was a valuable resource to her daughter and son-in-law. First, she took on the domestic duties, such as housekeeping and childrearing. Second, she had to provide physical care to family members, looking after her grandson. Third, she was responsible for maintaining the traditional culture (preparing ethnic foods, teaching her grandchild their native language and traditions) and preserving family practice.

Looking back at my childhood in Hong Kong, my ancestors played an influential role in modeling and teaching me Chinese cultural values. Through my observation of my grandfather's calligraphy practice (Story One) and devotion to the concept of 仁 (Humanness) (Story Two), I was able to embrace my Chinese roots and the Confucian philosophy. I wonder if Wilson will be able to have a similar appreciation for the gifts of learning his grandmother is offering him here in Canada. 
Research shows that immigrant parents who are more persistent in overcoming difficulties tend to inspire their children to do the same (Clauss-Ehlers \& Weist, 2004). They believe that if their children see them as adaptable and resilient figures, they will more easily integrate and be more motivated to thrive, especially at school. On the other hand, looking at the emotional and behavioural outcomes of Mr. Weareok, his child may be at risk for low motivation for school, as well as emotional withdrawal or behavioural outbursts. Although Mrs. Weareok seems to think positively, reassuring me that her family would bounce back from the difficulty, if violence continues in the home, their child may develop an inaccurate connection between the experiences at home and the outside world. In similar situations, children may feel a lack of control, hopelessness, and low self-worth (Massachusetts Advocates for Children, 2005). Such stressful family situations could lead to children who are ill-prepared to handle academic and social challenges in the classroom.

Harvey (1996) states that it is critical for educators to acknowledge their role in mitigating the negative impacts of the experience of trauma on children's cognitive, physical, social and emotional, and brain development. Early Childhood Educators are encouraged to construct a relational-based community, which is referred to as being an “ecological fit" (p. 20) environment. This relational-based approach promotes social competence and belonging, and foster individuals' ability to cope and build social relationships within our social context. We must be aware of the essence of quality environment-person relationships for children's well-being, regardless of whether children have experienced violence or not. 
A longitudinal study, exploring immigrant Latino parents' aspirations and expectations on their children's school performance, indicates parents' aspiration for children to excel at school (Goldenberg, Gallimore, Reese, \& Garnier, 2001). They emphasize that education attainment offers their children social and economic benefits, as well as personal development and satisfaction. In another study, educators revealed that Chinese immigrant parents often expect high marks from their children and place pressure on their academic achievement (Zhou, 2013). They express that parents are uninterested in supporting their child in learning how to interact with other students, and overemphasize academic achievement. Results show that children who were pushed to achieve parental expectations become self-conscious and more terrified to learn. In such situations, children may in turn suffer from anxiety and stress, something educators need to recognize and provide appropriate support and guidance.

\section{Looking back ... Moving forward ...}

The relationship (sociality), the temporality, and the places where events happened, the three-dimensional spaces of experience, are demonstrated throughout the three chapters of analysis. In chapter four, we looked at personal justification, where I interjected my inquirer voice with that of my storyteller one. In this chapter five, we moved to practical justification of Narrative Inquiry, by exploring the key narrative patterns (challenges in a new home, a sense of belonging, and perseverance) that emerged from my told stories. With the integration of scholarly research, I extended the interpretation of my inquiry puzzle into the professional context of Early Childhood Education, and how such stories may inform my professional practice. In the next chapter 
six, we move to the third level of analysis, social justification, where I will look more deeply into how my inquiry may bear significance to the greater society. 


\section{CHAPTER SIX}

\section{Third Level of Analysis: Social Justification}

In this chapter, I engage in the third level of analytical process (social justification) of Narrative Inquiry. Moving from examining the interim text (the told stories) to creating research text (narratives of experience), I revisit and critically analyze the narrative patterns: challenges in a new home, a sense of belonging, and perseverance. I continue to look deeply into their relevance to the inquiry puzzle, How do I, as an Immigrant-Early Childhood Educator, Experience Working With Immigrant Children and their Families? At this stage, I focus on asking the questions "So what?" and "Who cares?" to consider possible value and implications of my inquiry to the larger social context.

As I analyze the told stories, I continue to use the three-dimensional space (temporality, sociality, and place) of Narrative Inquiry while moving backward and forward, inward and outward, to deepen my understanding of how my stories of being an immigrant in Canada may inform how I and my colleagues work with immigrant children and their families, and why this is significant to the society at large.

Throughout the analytical process, I am cognizant that my reflection on, and examination of my own personal-professional experiences, may inspire readers to engage in their own experiences, and so deepen their own self-knowing of who they are as educators. This quality of invitation and transferability in Narrative Inquiry, demonstrates how individual stories of experience find broader meaning in society, beyond the immediate local context. 


\section{Challenges in a New Home}

As I examine the told stories in this inquiry, with the support of relevant scholarly literature, it is evident that immigrant children and their families are faced with numerous challenges during the settlement process. Like Mr. Weareok and Wilson's grandmother, their inability to communicate with others in English is one of the significant obstacles preventing them from fully engaging in the new society. To support immigrants' proficiency in English, the Canadian government and many non-profit organizations offer English classes to assist new immigrants, at their initial point of entry, in writing, reading, listening and speaking. Occupation-specific language training is also provided to instruct them in learning the language used specifically in their profession within the Canadian context. However, multilingual settlement services and counselling should be simultaneously delivered to immigrants as soon as we arrive. The purpose is not only to understand our settlement concerns, but also pre-migration and migration experiences, which help to identify each individual's unique stories and needs, and avoid using the “one-size fits all” model of practice. Connecting us with individuals or families of our own cultural and professional backgrounds, who had the experience of navigating the Canadian system (employment, housing, healthcare, education), can foster our social engagement and eliminate isolation.

Throughout this inquiry, I show the potential effects of integration challenges on family dynamics and triggering familial issues that lead to children's learning and wellbeing. For example, Wilson's grandmother's inability to communicate with others may become a burden for her family and affect her relationship with Wilson, and in turn causes frustration. All areas of professionals, including social workers, early childhood 
educators, health care specialists, psychologists, counsellors, settlement workers, school principals and teachers should work collectively together to share the knowledge on ways to minimize the systemic barriers and optimize the family system. While incorporating the strategies and expertise of the multiple disciplines, we should also acknowledge and respect the cultural differences of the families. In order to design and implement culturally appropriate plan and care, we should recognize our own biases and judgement towards cultural stereotypes and norms. The messages and conceptions of cultural diversity are predominately received and constructed within a social setting (Buchori \& Dobinson, 2015). It is very crucial that we, as professionals, are aware of and confront the use of language and policies in our practices that are discriminatory and reinforce stigmatization.

The professional integration problems of immigrant educators are compounded by their limited English proficiency and cultural differences from the receiving country (Myles et al., 2006; Niyubahwe et al., 2013). The lack of fluency in English hampers our access to employment and communication with our co-workers, and affects our confidence. For that reason, it is important to create on-going engagement activities within professional setting among staff and to build an inclusive community, where immigrant and non-immigrant educators listen and respect each other despite our cultural and linguistic differences.

\section{A Sense of Belonging}

Immigrants' maintenance of their own cultural identities and values are linked to their engagement with the receiving society and sense of belonging, which in turn heightens their contribution to Canada (Hou \& Bonikowska, 2016). I am familiar with 
feeling the lack of belonging, as my extended family disregarded my values. Therefore, professionals working with immigrant children and their families should respect and understand their already-established cultural rituals, beliefs, and behaviours, and integrate these into our professional guidelines and practices.

In my inquiry, immigrant's sense of belonging is intensified by the acculturation stress, which may lead to family conflicts and spousal abuse. According to Statistics Canada, women are at a higher risk of intimate partner violence than men (Mandell, 2005). Canadian Women's Foundation (2013) shows that " $83 \%$ of all police-reported domestic assaults are against women. This pattern is consistent for every province and territory across Canada" (p. 4). Report also suggests that certain factors such as one's economic status, as well as being an immigrant and a visible minority, play a role in exacerbating vulnerability. Therefore, immigrant women are situated in a very vulnerable position, like Mrs. Weareok. For abused immigrant women, they are likely to suffer from economic insecurity, social isolation, language barrier, and gendered-migration policies may increase their vulnerability to abuse.

Policy makers should draw closer attention to their immigration policies, such as assessing which category of professions are given preference in the Canadian society and ensure these privileges do not favour one gender over another, nor influence the eligibility for permanent residency. It is also important for community members who work with immigrant children and families to get involved in professional training on violence against immigrant women and intimate partner violence. We should examine the phenomenon critically through the ecological model and deal with it through the 
community, social, and political aspects, rather than viewing it as individual and family issues.

\section{Perseverance}

Due to limited English proficiency, immigrant adults experience a tremendous difficulty to engage in the labour market and social activities. To gain economic status and stability, they are willing to take on life risking and low wage job. With the lack of knowledge of legal and labour rights, they are more likely to be exploited (Vogel, 2009). There is a need to provide information sessions in their native language regarding their rights within various social settings (schools, hospitals, community centers, churches), in order to develop their awareness of how they are protected in the new country. Without adequate knowledge of the law and my rights, the fear of deportation prevented me from standing up for myself (Story Four). I wonder if Mrs. Weareok was feeling the same (Story Five).

It is crucial to recognize the effects of migration on immigrants' physical, social, emotional, and psychological well-being while facing the pressure to survive in the new country and support the family. In my told stories, Wilson's grandmother, the Weareok family, and I demonstrate the spirit to survive and to thrive in Canada. While some immigrants may exhibit the risk of mental health issues, such as depression, like Mr. Weareok, others may internalize their emotions or deny being unwell. Being members of our community and society, we need to be more in tune with others, especially new immigrants, who may be struggling and in need of support. When we see individuals who encounter difficulty of expressing themselves, using non-verbal communication strategies to discover their thoughts could be helpful. Using our patience, kindness, and sincerity to 
welcome new immigrants into our society, and simultaneously, respect and learn about their cultural values, beliefs, and moral, could go a long way towards helping immigrant children and their families feel welcome.

Children, including those new to this country, are the next generation of contributors to this rich and complex society. It would be beneficial to give them voice to share their immigration experiences and how the observations of their families' acculturation experiences influence the way they engage in their new home. Therefore, I believe that further research needs to be undertaken with immigrant children, to learn how moving to a new country looks from their perspective.

\section{Looking back ... Moving forward ...}

In this chapter, we looked at the third level of analysis process of Narrative Inquiry, social justification. By exploring my own storied experiences as an immigrant and Early Childhood Educator, I hope to have shed light on why it is vital to hear the voice of immigrants and what is important to us. I have continued to engage in the threedimensional space and the four directions of Narrative Inquiry, to highlight why this inquiry may be valuable to the greater society. In the next chapter, I reconstruct my told stories into the narrative form of a letter written to immigrant children. 


\section{CHAPTER SEVEN}

\section{Social Significance}

In this chapter, I gather my multiple "I's" (first-born child, grandchild, immigrant, Early Childhood Educator, inquirer, story-teller) to write a letter to the immigrant children in my professional care. I use this letter to communicate and connect with them in response to my personal and professional experiences working with them and their families, and other fellow immigrant peers. By writing this letter, I express what I promise to do, as a professional, based on what I have learned from my own selfexploration and reflection (self-study), using Arts-Informed Narrative Inquiry.

Dear Children,

“Welcome to Canada!" Do you remember hearing this greeting from an immigration officer when you arrived at the airport in Canada? For me, I remember that moment very clearly. I was excited and curious to explore the new country, similar to how it feels when we discover a new playground. But the longer I stayed, the more frustrated, scared, and lonely I felt. Unlike the slides and swings I used to play on. The slide in this playground is harder to climb, the monkey bars are more difficult to grip, and the swings are so small that I cannot fit in. Most importantly, other children who are playing do not seem to notice me.

This is how I feel as an immigrant in Canada facing and overcoming many challenges. I struggle with communicating with other people, making friends, adapting to the new culture, and finding a job. When I am treated unfairly and disrespectfully, I feel scared to tell anyone because I am afraid they will send me away. I only have the courage and language ability to share with the doctor my physical illnesses, but not the discomfort I feel inside. I try to talk to my family who live back home, but they do not seem to understand my situation. Although my extended family provides me with a place to stay, my new life is controlled by their 
rules. I feel sad and constrained. Not only do I feel like an outsider to the new country and my new family, but also to my own family back home.

Working with you and your families in the classroom, I notice many of you share similar immigration experiences with me. Despite having challenges in adjusting to the classroom routine and certain activities, such as circle time, naptime, or art activities, you demonstrate the ability to make connections with other children in your own way. You continue to speak to them in your own language, as they respond to you in theirs. This interaction does not impair your relationships. It showcases your strength to listen and negotiate the differences with your peers. You truly inspire me to re-examine my current pedagogical practices and ways to engage with you and your families.

Understanding that you may not be familiar with the expectations, rituals, activities, and norms established in the classroom, I am open to learn about your cultural rituals and experiences in learning, and design a culturally responsive and sensitive curriculum. I commit to respect your rooted cultural values and practices, as I recognize that the maintenance of our heritage contributes to our integration in the new country. I continue to implement different strategies to foster your social and emotional connections with peers, your family, and me. For example, using on-going observations, appropriate non-verbal communication skills, and incorporating open-ended (no rules to follow, use, or function) materials to explore how you learn.

You may witness your family suffering from distress because they experience language barriers and un- or under-employment. They can no longer speak kindly and patiently with each other, and you are scared because you see them crying or do not see them at all, as they have to work constantly to support the family. You see that their settlement process is obstructed while you are well-adjusted in school. Does that affect your relationship with your family? For some of you who have younger siblings at home, do you feel pressured to look after them and 
take on the parental role, as your parents try to overcome various hurdles? Do you feel guilty not to contribute to the household because your family sacrificed their life for your future? I promise I will conduct more research in order to better understand you and your families. I promise to listen to you. I want to hear your stories.

As an Early Childhood Educator, and immigrant myself, I know the importance of social and economic security for immigrant families, and how your well-being and learning are directly affected, if these needs are not being met. To ensure that you grow in a healthy and secure environment, I strive to support your family to break through the layers of systemic barriers. I will connect with the community service providers (heath care practitioner, employment counsellor, settlement worker, public librarian, legal aid specialist) around the community to offer information and resources that may alleviate their stress. I will continue to reach out to your families, other early childhood professionals, and researchers to form a support committee, using an evidence-informed approach, to inform the government about what you and your family need.

I will work collectively with my colleagues to learn more about the immigration movement and policies within and beyond the Canadian context, in order to gain a better understanding of how social, economic, and national forces shape the immigration atmosphere. We will work hard to maintain the quality of our practices and our educational programs of Early Childhood Education. Working as a collaborative unit, we will ensure that we are supportive of each other, especially the novice Early Childhood Educators.

Further, I will strive to have ongoing reflective practice, an important part of our continued competence, as Early Childhood Educators. In this way, we will continue to promote the development of our personal knowledge, using creative arts to first understand who we are as educators, so that we can be more fully available to support you and your families. 
I want you to know that I am not only a teacher, but also a human being who aims to provide you and your family with care, patience, kindness, compassion, and empathy. I am dedicated to continue to connect with you at a professional, personal, and human level in the new playground, which is your home in Canada - a playground that celebrates inclusion and thriving relationships.

With respect, Your Immigrant-Early Childhood Educator Helen Kwok

\section{Looking back ... Moving forward ...}

In this chapter, I reconstructed my told stories and from that learning I created a narrative in form of a letter. I dedicated this letter to the immigrant children in my care. I identified ways I promise to keep, as an Early Childhood Educator, in order to better serve the immigrant children and their families. In the final chapter, I share what I have learned from undertaking this self-study, using Arts-Informed Narrative Inquiry, and where I am heading as an Early Childhood Educator. 


\section{EPILOGUE}

\section{What I Have Learned on this Journey of Inquiry}

I am situated at the end of my Masters Research Paper, embracing my experience of engaging in the Arts-Informed Narrative Inquiry self-study. Using a series of creative art activities (drawings, journal-writing, metaphoric reflection, and photographs), I am able to discover in-depth knowledge of myself, as a person and a professional. Adopting the theoretical lens of Narrative Inquiry, I recognize that my entire learning, analytical and interpretation processes are operated in a non-linear manner.

Through the three-dimensional space (temporality, sociality, and place) and four directions (inward and outward, backward and forward) of Narrative Inquiry, I consistently shift back and forth temporally (grandchild, first-born child, immigrant, Early Childhood Educator), socially (relationships with my grandfather, my sibling, my mother, extended family, Mrs. Weareok, and Wilson's grandmother, as well as my storyteller-I in relationship with my inquirer-I), and in places (Hong Kong and Canada). As I reflect, examine, and analyze the told stories, I am able to relate to the emotions and perspectives of the multiple "I's" and gain a better insight into my experience of working, as an immigrant-Early Childhood Educator, with immigrant children and their families. 


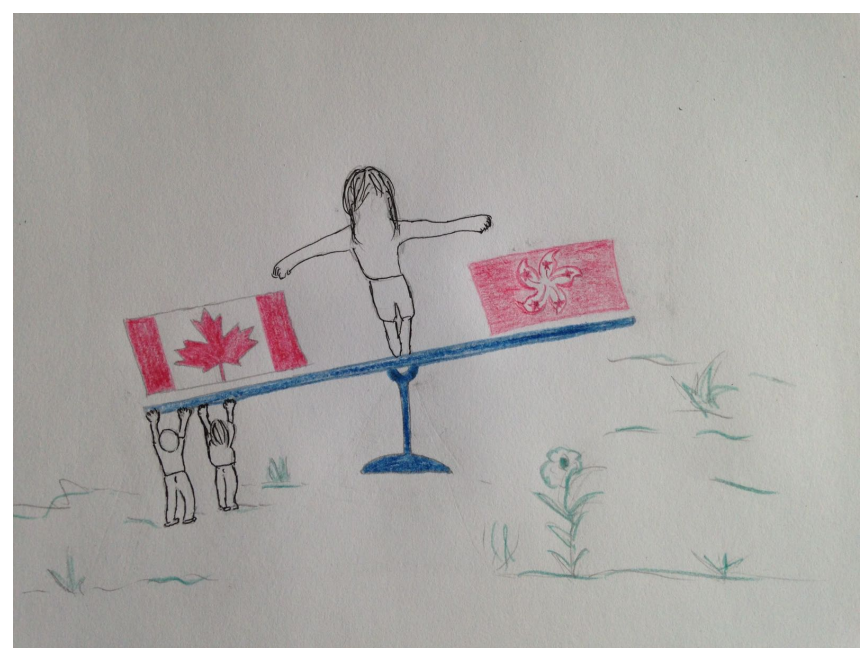

Figure 1. A depiction of what I learned as an immigrant-Early Childhood Educator.

As a new immigrant whose Chinese roots are deeply entrenched into my value, moral, and cultural systems, I am simultaneously adjusting to the Canadian culture. I constantly struggle to maintain the balance between my heritage and the Canadian norms. The drawing depicts how I try to balance both flags and cultural identities (Canada and Hong Kong). Leaning on one side more than the other, I face the risk of losing one of the flags. Dealing with the situation alone, I feel insecure and scared of holding onto one side tighter than the other. As a result, I feel helpless and unsure of where I truly belong.

Working with immigrant children and their families, we share our immigration experiences, and that draws us closer together. However, I need to be mindful of how my internal and external struggles, as an immigrant, may influence my professional practices, which in turn affects the learning of children in my professional care. Looking back at Mrs. Weareok's and Wilson's grandmother's stories, they demonstrate the negative impact of the family's acculturation experience on family dynamics and functioning, and how it may ultimately impair parent-child and grandparent-grandchild relationships. As the family system becomes unstable, children's well-being and developmental trajectory 
are more likely to be disrupted. Therefore, in my drawing, I want to express how immigrant children may be the ones, holding up the lever, trying to keep the family balanced. Especially those who are taking on parental roles of their younger siblings while their parents need to work hard to sustain their living outside the home.

This inquiry illustrates my personal and professional experiences of working with immigrant children and their families. It is evident that immigrant-Early Childhood Educators have a lot to offer in the field of Early Childhood Education. However, there is a lack of attention paid to their own immigration challenges related to their personal and professional experiences, while working within a culturally diverse classroom and society. Therefore, I hope this inquiry will inspire my colleague - Early Childhood Educators to consider the key narrative patterns that emerged in my stories of immigration experience, and to reflect upon their own personal-professional experiences, through creative self-expression approaches, and in this way to contemplate how their values and beliefs might inform their professional practice. Through this, we can provide further evidence for other professionals, political parties, and policy makers, to reflect on their respective roles in supporting not only the immigrant-Early Childhood Educators, but also the entire immigrant population.

Looking back on my Arts-Informed Narrative Inquiry self-study, I recognize how my explorer narrative thread runs through my personal and professional life. I first noticed it when I was curious to explore a shopping mall, at age six (Story Two), and then when I migrated to Canada as a young teen, wanting to discover a new country (Story Four). And recently, when I encountered Arts-Informed Narrative Inquiry selfstudy. Through these explorations I discover my imagination, inclination to take 
calculated risks, and willingness to be vulnerable. These journeys enrich my soul, allowing me to expand my horizons, to grow, and to fully live the concept of 仁 (Humanness). 


\section{REFERENCES}

Adair, J. (2011). Confirming chanclas: What early childhood teacher educators can learn from immigrant preschool teachers. Journal of Early Childhood Teacher Education, 32(1), 55. doi: 10.1080/10901027.2010.547652

Adair, J. K., Tobin, J., \& Arzubiaga, A. E. (2012). The dilemma of cultural responsiveness and professionalization: Listening closer to immigrant teachers who teach children of recent immigrants. Teachers College Record, 114(12).

Ali, M. A. (2012). The shadow of colonialism on relations between immigrant parents and their children's teachers. Alberta Journal of Educational Research, 58(2), 198.

Bacallao, M. L., \& Smokowski, P. R. (2007). The costs of getting ahead: Mexican family system changes after immigration. Family Relations, 56(1), 52-66. doi:

10.1111/j.1741-3729.2007.00439.x

Bascia, N. (1996). Inside and outside: Minority immigrant teachers in Canadian schools. Qualitative Studies in Education, 9(2), 151-165.

Beaman, L. A. (2012). Social networks and the dynamics of labour market outcomes: Evidence from refugees resettled in the U.S. The Review of Economic Studies, 79(1), 128-161. doi: 10.1093/restud/rdr017

Bean, F. D., \& Bell-Rose, S. (Ed.). (2003). Immigration and opportunity: Race, ethnicity, and employment in the united states. New York: Russell Sage Foundation.

Bernhard, J. K., Hyman, I., \& Tate, E. (2010). Meeting the needs of immigrants throughout the life cycle. Retrieved from http://www.peelregion.ca/socialservices/pdfs/discussion-paper-2.pdf 
Beyer, C. K. (2010). Innovative strategies that work with nondiverse teachers for diverse Classrooms. Journal Of Research In Innovative Teaching, 3(1), 119-129.

Boyd, D. (2006). Resilience in newcomer families. Canadian Issues, 85(1), 85-86.

Brandon, P. (2004). The childcare arrangements of preschool aged children in immigrant families in the United States. International Migration Review, 42(1), 65-87.

Buchori, S., \& Dobinson, T. (2015). Diversity in teaching and learning: Practitioners' perspectives in a multicultural early childhood setting in Australia. Journal of Early Childhood, 40(1), 71-79.

Bullough, R., \& Pinnegar, S. (2001). Guidelines for quality in autobiographical forms of self-study research. Educational Researcher, 3(2), 13-21.

Canada Women's Foundation (2013). Moving women out of violence. Retrieved from http://www.canadianwomen.org/sites/canadianwomen.org/files/imports/PDFFactSheet-StopViolence-March2013.pdf

Canadian Council for Refugees. (2010). Talking about refugees and immigrants: a glossary. Retrieved from http://ccrweb.ca/sites/ccrweb.ca/files/glossary en.pdf

Canadian Council for Refugees. (n.d.). Re: Violence against newcomer women [Online forum]. Retrieved from http://ccrweb.ca/en/violence-against-women

Capps, R., Fix, M., Murray, J., Ost, J., Passel, J. S., \& Hernandez, S. H. (2006). The new demography of America's schools: Immigration and the No Child Left Behind Act. Retrieved from http://www.urban.org/UploadedPDF/311230_new_ demography.pdf

Card, D., \& Raphael, S. (Ed.). (2013). Immigration, poverty, and socioeconomic inequality. New York: Russell Sage Foundation. 
Chen, D. W., Nimmo, J., \& Fraser, H. (2009). Becoming a culturally responsive early childhood educator: A tool to support reflection by teachers embarking on the anti-bias journey. Multicultural Perspectives, 11(2), 101-106.

Chiu, M. M., Pong, S., Mori, I., \& Chow, B. W. (2012). Immigrant students' emotional and cognitive engagement at school: A multilevel analysis of students in 41 countries. Journal of Youth and Adolescence, 41(11), 1409-1425. doi:10.1007/s10964-012-9763-x

Chuang, S. S., \& Moreno, R. P. (2011). Immigrant children: Change, adaptation, and cultural transformation. United Kingdom: Lexington Books.

Citizenship and Immigration Canada. (2010). Canada facts and figures: immigration overview - permanent and temporary residents. Glossary of terms and concepts. Retrieved from http://www.cic.gc.ca/english/pdf/research-stats/facts2010.pdf

Clandinin, D. J \& Rosiek, J. (2007). Mapping a landscape of narrative inquiry: Borderland spaces and tensions. In J. Clandinin (Ed.), Handbook of narrative inquiry: Mapping a methodology (pp. 35-76). Thousand Oaks: Sage.

Clandinin, D. J. (2013). Engaging in Narrative Inquiry. United States of America: Left Coast Press Inc.

Clandinin, D. J. \& Connelly, F. M. (1994). Personal experience methods. The SAGE handbook of qualitative research (pp. 413-427). Thousand Oaks: Sage.

Clandinin, D. J. \& Connelly, F. M. (2000). Narrative inquiry: Experience and story in qualitative research. San Fransisco, CA: Jossey-Bass. 
Clandinin, D. J., \& Connelly, F. M. (1998). Personal experience methods. In N. K. Denzin, \& Y. S. Lincoln (Eds.), Collecting and interpreting qualitative materials (pp. 150-177). Thousand Oaks, CA: Sage Publications Inc.

Clandinin, D. J., Pushor, D., \& Orr, A. M. (2007). Navigating sites for Narrative Inquiry. Journal of Teacher Education, 58(1), 21-35. doi: 10.1177/0022487106296218

Clauss-Ehlers, C. S., \& Weist, M. D. (2004). Community planning to foster resilience in children. New York: Kluwer Academic.

Connelly, F. M. \& Clandinin, D. J. (1990). Stories of experience and narrative inquiry. Educational Researcher, 19(5), 2-14. Retrieved from http://www.tc.umn.edu/ dillon/CI 8148 Qual Research/Session 12/Narrat iveClandinin ER article.pdf

Connelly, F. M. \& Clandinin, D. J. (2006). Narrative inquiry. In J. L. Green, G. Camilli, \& P. Elmore (Eds.), Handbook of complementary methods in education research (3rd ed., pp. 477-487). Mahwah, NJ: Lawrence Erlbaum.

Costigan, C. L., \& Dokis, D. P. (2006). Relations between parent-child acculturation differences and adjustment within immigrant chinese families. Child Development, 77(5), 1252-1267. doi: 10.1111/j.1467-8624.2006.00932.x

Cruickshank, K. (2004). Toward diversity in teacher education: Teacher preparation of immigrant teachers. European Journal of Teacher Education, 27(2), 125-138.

Curran, M. E. (2003). Linguistic diversity and classroom management. Theory Into Practice, 42(4), 334-340.

Delano-Oriaran, O. O., \& Meidl, T. D. (2012). Critical conversations: Developing white teachers for diverse classrooms. Journal Of Praxis In Multicultural Education, 
7(1), 1-27. doi: 10.9741/2161-2978.1042

DeVries, R., Zan, B., Hildebrandt, C., Edmiaston, R., \& Sales, C. (2002). Developing constructivist early childhood curriculum: Practical principles and activities. New York, NY: Teachers College Press.

Dewey, J. (1997). Experience and education. (New York, Touchstone). (Original work published 1938.)

Expósito, S., \& Favela, A. (2003). Reflective voices: Valuing immigrant students and teaching with ideological clarity. The Urban Review, 35(1), 73-91. doi: 10.1023/A:1022597607497

Foner, N., \& Dreby, J. (2011). Relations between the generations in immigrant families. Annual Review of Sociology, 37(1), 545-564. doi: 10.1146/annurev-soc-081309150030

Goldenberg, C., Gallimore, R., Reese, L., \& Garnier, H. (2001). Cause or effect? A longitudinal study of immigrant latino parents' aspirations and expectations, and their children's school performance. American Educational Research Journal, 38(3), 547-582. doi: 10.3102/00028312038003547

Goodwin, A. L. (2002). Teacher preparation and the education of immigrant children. Education and Urban Society, 34(2), 156-172. doi: $10.1177 / 0013124502034002003$

Gordon, J. A. (1996). Teachers from different shores. Equity and Excellence in Education, 29(3), 28-36.

Guruge, S., Roche, B., \& Catallo, C. (2012). Violence against women: An exploration of the physical and mental health trends among immigrant and refugee women in 
Canada [Special issue]. Nursing Research and Practice, 2012. doi:

$10.1155 / 2012 / 434592$

Guruge, S., Shirpak, K. R., Hyman, I., Zanchetta, M., Gastaldo, D., \& Sidani, S. (2010).

A meta-synthesis of post-migration changes in marital relationships in Canada.

Canadian Journal of Public Health, 101(4), 327-331. Retrieved from

http://search.proquest.com.ezproxy.lib.ryerson.ca/docview/763129787?pq-

origsite $=$ summon

Han, H., \& Thomas, M. (2010). No child misunderstood: enhancing early childhood teachers' multicultural responsiveness to the social competence of diverse children. Early Childhood Education Journal, 37(6), 469-476.

doi:10.1007/s10643-009-0369-1

Harvey, M.R. (1996). An Ecological View of Psychological Trauma and Trauma

Recovery. Journal of Traumatic Stress, (9)1, 3-23.

Heise, L., \& Garcia-Moreno. (2002). Violence by intimate partners. In E.G. Krug et al., (Eds., pp. 87-121), World report on violence and health. Geneve: World health Organization. Retrieve from http://www.who.int/violence injury prevention/violence/world_report/en/FullRV $\underline{\text { H.pdf }}$

Hernandez, D. J., \& Cervantes, W. D. (2011). Children in Immigrant Families: Ensuring opportunity for every child in America. Washington, DC: First Focus.

Hou, F., and Bonikowska, A. (2016). Educational and Labour Market Outcomes of Childhood Immigrants by Immigration Class. Analytical Studies Branch Research 
Paper Series, no. 377. Statistics Canada Catalogue no. 11F0019M. Ottawa: Statistics Canada.

Hou, F., Schellenberg, G., \& Berry, J. (2016). Patterns and determinants of immigrants' sense of belonging to Canada and their source country. Statistics Canada. Retrieved from http://www.statcan.gc.ca/pub/11f0019m/11f0019m2016383eng.htm

Hutchison, C. B. (2005). Teaching in America: a cross-cultural guide for international teachers and their employers. Dordrecht: Springer.

Hyman, I., Guruge, S., \& Mason, R. (2008). The impact of migration on marital relationships: A study of ethiopian immigrants in toronto. Journal of Comparative Family Studies, 39(2), 149-163.

Johnson, D., \& Larke, P. J. (2012). Three elements to educate teachers to work in diverse schools. National Forum Of Multicultural Issues Journal, 8(1), 29-39.

Karoly, L. A., \& Gonzalez, G. C. (2011). Early care and education for children in immigrant families. The Future of Children, 21(1), 71-101.

Keat, J. B., Strickland, M. J., \& Marinak, B. A. (2009). Child voice: How immigrant children enlightened their teachers with a camera. Early Childhood Education Journal, 37(1), 13-21. doi: 10.1007/s10643-009-0324-1

Keengwe, J., \& Oncwari, G. (2014). Cross-cultural considerations in the education of young immigrant learners. Beaverton: Ringgold Inc.

Kim, O. (1999). Mediation effect of social support between ethnic attachment and loneliness in older Korean immigrants. Research in Nursing and Health, 22, 169175. 
Kirmayer, L. J., Narasiah, L., Munoz, M., Rashid, M., Ryder, A. G., Guzder, J., \& Pottie, K. (2011). Common mental health problems in immigrants and refugees: general approach in primary care. Canadian Medical Association Journal, 183(12), 959967.

Kirova, A. (2001). Loneliness in immigrant children: Implications for classroom practice. Childhood Education, 77(5), 260. doi: 10.1080/00094056.2001.10521648

Kishor, S., \& Johnson, K. (2004). Profiling domestic violence-a multi-country study. Calverton, Maryland: ORC Macro. Retrieve from http://dhsprogram.com/pubs/pdf/od31/od31.pdf

Kurbegovic, D. (2016). A survey study examining teachers' perceptions in teaching refugee and immigrant students. Research in Comparative and International Education, 10(1), 95-119. doi: 10.1177/1745499914567821

Kwok, O. L. (2015). Early childhood educators' competence in creating a culturally responsive classroom. Unpublished manuscript, The school of Early Childhood Education, Seneca College, Toronto, Canada.

Ladson-Billings, G. (2006). It's not the culture of poverty, it's the poverty of culture: The problem with teacher education. Anthropology and Education Quarterly, 37(2), $104-109$.

Lee, J., \& Pacini-Ketchabaw, V. (2011). Immigrant girls as caregivers to younger siblings: A transnational feminist analysis. Gender and Education, 23(2), 105119. doi: $10.1080 / 09540251003674063$

Lee, S., \& Dallman, M. E. (2008). Engaging in a reflective examination about diversity: Interviews with three preservice teachers. Multicultural Education, 15(4), 36-44. 
Lewis-Watts, L. (2006). Speaking with families from within the 'family class'. Canadian Issues, 81(6), 81-84.

Lindsay, G. M., \& Schwind, J. K. (2016). Narrative inquiry: Experience matters. Canadian Journal of Nursing Research, 48(1), 14-20. doi: $10.1177 / 0844562116652230$

Madhavi, A V Pramuditha., Guruge, S., Schwind, J. K., \& Martin, L. S. (2014). Exploring the experience of loneliness among older sinhalese immigrant women in canada. Perspectives, 37(1), 6.

Mandell, N. (2005). Feminist issues: Race, class, and sexuality (4th ed.). Toronto, ON: Pearson-Prentice Hall.

Massachusetts Advocates for Children. (2005). Report of the APA Task Force on Helping Traumatized Children Learn. Retrieved from https://traumasensitiveschools.org/tlpi-publications/download-a-free-copy-ofhelping-traumatized-children-learn/

Massachusetts Teachers Association. (2008). Tomorrow's teachers: Preparing the education workforce for 21" century schools. Boston, MA: Center for Education Policy and Practice.

Meier, D. R., \& Stremmel, A. J. (2010). Reflection through narrative: The power of narrative inquiry in early childhood teacher education. Journal of Early Childhood Teacher Education, 31(3), 249-257. doi:

$10.1080 / 10901027.2010 .500538$ 
Mohr, Kathleen A. J., \& Mohr, E. S. (2007). Extending english-language learners' classroom interactions using the response protocol. The Reading Teacher, 60(5), 440-450. doi: 10.1598/RT.60.5.4

Myles, J., Cheng, L., \& Wang, H. (2006). Teaching in elementary school: Perception of foreign-trained teacher candidates of their teaching practicum. Teaching and Teacher Education, 22(2), 233-245.

Nieto, S., \& Bode, P. (2008). Affirming diversity: The sociopolitical context of multicultural education (5th Ed. ed.). Boston: Pearson.

Niyubahwe, A., Mukamurera, J., \& Jutras, F. (2013). Professional integration of immigrant teachers in the school system: A literature review. McGill Journal of Education, 48(2), 279-296. doi: 10.7202/1020972

Peeler, E., \& Jane, B. (2005). Efficacy and identification of professional self. Academic Exchange Quarterly, 9(4), 224.

Pemberton, S., \& Tremblay, L. (2016, November). Journey in a new world: Strategies to ease integration for newcomer families. Interaction, 30(2). Retrieved from http://www.cccf-fcsge.ca/wp-content/uploads/InterVol302-ENG.pdf

Phillion, J. (2003). Obstacles to accessing the teaching profession for immigrant women. Multicultural Education, 11(1), 41-46.

Remennick, L. (2002). Survival of the fittest: Russian immigrant teachers speak about their professional adjustment in Israel. International Migration, 40(1), 99-121.

Sanders, J., Nee, V., \& Sernau, S. (2002). Asian immigrants' reliance on social ties in a multiethnic labor market. Social Forces, 81, 281- 314. doi: 10.1353/sof.2002.0058 
Schmidt, C. (2010). Systemic discrimination as a barrier for immigrant teachers. Diaspora, Indigenous, and Minority Education, 4(4), 235-252. doi: $10.1080 / 15595692.2010 .513246$

Schwind, J. K. (2003). Reflective process of the study of illness stories as experienced by three nurse teachers. Reflective Practice, 4(1), 19-12. doi: $10.1080 / 1462394032000053521$

Schwind, J. K. (2008). Accessing humanness: From experience to research, from classroom to praxis. In J. K. Schwind \& G. M. Lindsay (Eds., pp. 77-94). From experience to relationships: Reconstructing ourselves in education and healthcare. Charlotte, NI: Information Age Publishing.

Schwind, J. K. (2016). Narrative reflective process: A creative experiential path to personal-knowing in teaching-learning scholarship. In J. Gingras, P. Robinson, J. Waddell, \& L.D. Cooper (Eds.), Teaching as scholarship: Preparing students for professional practice in community services (pp. 137-154). Waterloo, ON: Wilfrid Laurier University Press.

Schwind, J. K., \& Lindsay, G. M. (2016). Arts-informed narrative inquiry: Crossing boundaries of research and teaching-learning. Learning Landscapes, 9(2), 473487.

Schwind, J. K., Cameron, D., Franks, J., Graham, C., \& Robinson, T. (2012). Engaging in Reflective practice to fine tune self-as-instrument-of-care. Reflective Practice, 13(2), 223. doi: 10.1080/14623943.2011.626030

Schwind, J. K., Fredericks, S., Metersky, K., \& Porzuczek, V. G. (2016). What can be learned from patient stories about living with the chronicity of heart illness? A 
narrative inquiry. Contemporary Nurse, 52(2-3), 216-229.

doi:10.1080/10376178.2015.1089179

Schwind, J. K., Lindsay, G. M., Coffey, S., Morrison, D., \& Mildon, B. (2014). Opening the black-box of person-centred care: An arts-informed narrative inquiry into mental health education and practice. Nurse Education Today, Special Issue NET 2013, 34(8), 1167-1171. doi: 10.1016/j.nedt.2014.04.010

Seah, W. T. (2005). Negotiating about perceived value differences in mathematics teaching: The case of immigrant teachers in Australia. In H. L. Chick, \& J. L. Vincent (Eds.). Proceedings of the 29th conference of the International Group for the Psychology of Mathematics Education (Vol. 4, pp. 145-152). Melbourne, AU: Department of science and mathematics education, University of Melbourne.

Shields, C., Novak, N., Marshall, B., \& Yallop, J. J. G. (2011). Providing visions of a different life: Self-study narrative inquiry as an instrument for seeing ourselves in previously-unimagined places. Narrative Works, 1(1), 63-77.

Sodowsky, G. R., Kwan, K. L. K., \& Pannu, R. (1995). Ethnic identity of Asians in the United States. In J. G. Ponterotto, J. M. Casas, L. A. Suzuki, \& C. M. Alexander (Eds.), Handbook of multicultural counseling (pp. 123-154). Thousand Oaks, CA: Sage Publications.

Stewart, D. E., Gagnon, A. J., Merry, L. A., \& Dennis, C. (2012). Risk factors and health profiles of recent migrant women who experienced violence associated with pregnancy. Journal of Women's Health, 21(10), 1100-1106. doi:

$10.1089 /$ jwh.2011.3415 
Strickland, M. J. (2012). Storylines: Listening to immigrant students, teachers, and cultural-bridge persons making sense of classroom interactions. Middle Grades Research Journal, 7(2), 77.

Suarez-Orozco, C., \& Suarez-Orozco, M. M. (2001). Children of immigration. Cambridge, MA: Harvard University Press.

Sue, D. W., \& Sue, D. (2003). Counseling the culturally diverse: Theory and practice (4th ed.). New York: Wiley.

Tastsoglou, E., \& Jaya, P. S. (2011). Immigrant women in atlantic canada: Challenges, negotiations, and re-constructions. Toronto: Canadian Scholars' Press/Women's Press.

Thomas, S., \& Kearney, J. (2008). Teachers working in culturally diverse classrooms: Implications for the development of professional standards and for teacher education. Asia-Pacific Journal Of Teacher Education, 36(2), 105-120. doi: $10.1080 / 13598660801971625$

Tsung, T., Freeman, R., \& White, B. (2007). Implementing multicultural education in PreK-3rd grade classrooms through the empowerment of teachers, children, and families. The International Journal of Learning: Annual Review, 12(5), 17-22. doi: 10.18848/1447-9494/CGP/v14i05/45339

Vogel, D. (2009). Stories and reflections of immigrant activists in europe. Bern: Peter Lang.

Vuckovic, A. (2008). Making the multicultural learning environment flourish: The importance of the child-teacher relationship in educating young children about diversity. Australian Journal Of Early Childhood, 33(1), 9-16. 
Wang, T. (2003). Cultural dissonance and adaptation: A study of Chinese immigrant teachers coping with cultural differences in Toronto schools (Unpublished doctoral dissertation). University of Toronto, Toronto, ON.

Weiss, R. S. (1973). Loneliness: The experience of emotional and social isolation. Cambridge, MA: MIT Press.

World Health Organization. (2012). Understanding and addressing violence against women. Retrieved from http://apps.who.int/iris/bitstream/10665/77433/1/WHO_RHR_12.35_eng.pdf

Xie, X., \& Xia, Y. (2011). Grandparenting in chinese immigrant families. Marriage \& Family Review, 47(6), 383-396. doi: 10.1080/01494929.2011.594218

Zhou, G. (2013). What are Chinese immigrant parents' concerns with their children's education? Working paper No. 2013/4. Retrieved from http://www.ryerson.ca/content/dam/rcis/documents/RCIS_WP_Zhou_No_2013_4 .pdf 


\section{Appendix A}

\section{Ethics Application - No REB Review Required}

Tue, Mar 28, 2017 at 8:41 AM

Re: REB 2017-106 The title of my research is:

Early Childhood Educator's Experience of Working with Immigrant Children and Their Families: An Arts-Informed Narrative Inquiry self-study

Dear Oi Ling (Helen) Kwok,

The Research Ethics Board has determined that your protocol does not require its review.

Thank you for submitting your application for ethics review for the above noted project. Based on the information provided it has been determined that the project is exempt from review. Because the work involves only your own reflections on your work, and does not include telling the stories of others and no others will be identified in the work, ethics review is not required. Should your proposed methodology change, pelase reapply to the REB for ethics review and approval. Good luck wiht the project.

If you have any questions regarding your submission or the review process, please do not hesitate to get in touch with the Research Ethics Board (contact information below).

Record respecting or associated with a research ethics application submitted to Ryerson University.

NOTE: This email account (rebchair@ryerson.ca) is monitored by multiple individuals. If you wish to contact a specific member of the Research Ethics Board, please do so directly.

Yours sincerely,

Dr. Nancy Walton, $\mathrm{PhD}$

Co-Chair

Ryerson Research Ethics Board

416-212-4952

nwalton@ryerson.ca

AND

Dr. Chris MacDonald, PhD

Co-Chair

Ryerson Research Ethics Board

416-979-5000 ext. 6093

Chris.macdonald@ryerson.ca

Toni Fletcher, MA

Research Ethics Co-Ordinator

(416)979-5000 ext. 7112

toni.fletcher@ryerson.ca 